\title{
Palabras Asesinas: Una aproximación al tema de la represión de la masonería en la guerra civil y durante el franquismo
}

\section{Killer Words: A New Approach to the Issue of the Repression of Freemasonry During the Spanish Civil War and the Franco Regime}

\author{
Juan José Morales Ruiz \\ Universidad de Educación a Distancia, España \\ jmorales@calatayud.uned.es
}

Recepción: 1 de abril de 2019/Aceptación: 24 de mayo de 2019.

doi: https://doi.org/10.15517/rehmlac.v11i1.36804

Palabras clave

Franquismo; dictadura; represión; conspiración; antimasonería.

Keywords

Francoism; dictatorship; repression; conspiracy; anti-freemasonry.

Resumen

En este artículo estudio el tema de la represión de la masonería en la guerra civil y durante el franquismo, desde el análisis del discurso antimasónico publicado durante este período histórico, que abordo en mi libro "Palabras Asesinas". Creo que contra la masonería se desarrolló un discurso que perseguía la aniquilación moral de los masones, además de la brutal represión física que se llevó a cabo. Eran palabras que hieren, palabras que matan, palabras asesinas.

Abstract

In this article I study the repression of Freemasonry during the Spanish civil war and the Franco regime, through an analysis of the anti-Masonic discourse published during this historical period, which I address in my book "Killing Words". I argue that a discourse against Freemasonry was developed during those periods that sought the moral annihilation of the Freemasons, in addition to the brutal physical repression that took place. Such words were words that hurt and kill, they were killer words, as I discussed in this article.

\section{El país de la desmemoria}

Me interesaría hacer algunas consideraciones previas que tienen que ver con la actualidad cuando nos planteamos la historia del pasado inmediato. Recordaré lo que escribe Juan Miguel Baquero en El país de la desmemoria, del genocidio franquista al silencio interminable:

No hay nada más brutal que el contraste entre la impunidad de los crímenes cometidos desde el 17 de julio de 1936 por los sublevados contra el legítimo gobierno de la 
Segunda República, por un lado, y el desprecio del Estado, por otro, a las víctimas de la conspiración armada. Un claro síntoma de la herida abierta, de un olvido insostenible en cualquier nación democrática homologable a la española, que deja al descubierto la herencia diseñada por los golpistas, continuada por sus herederos y que a lo largo de cuatro décadas de democracia ha sido imposible romper (...)

España es el país de la desmemoria. Una tierra enmarañada en la lectura parcial de su propio relato, que ha vendido durante años una visión equidistante o directamente apologética de su cruel pasado reciente como alimento propiciatorio del franquismo sociológico (...) Que España sea como es no parece casual. La idiosincrasia hispana gestada al cobijo de la mano alzada de Franco produce monstruos. Es una sociedad que tolera la existencia de miles de fosas comunes barridas bajo la alfombra; una anomalía democrática de tal calibre que mantiene impunes los crímenes franquistas contra la humanidad mientras la única pena recae sobre los propios represaliados, condenados al olvido y el desprecio.

Porque el Estado no ha garantizado hasta ahora el acceso a la verdad, la justicia ni la reparación, exigidas por Naciones Unidas como requisito indispensable para cimentar las garantías de no repetición de las graves violaciones de los derechos humanos perpetradas desde el estallido golpista. Tras cuatro décadas de democracia, España todavía protege a los herederos del pasado más oscuro de la nación (...) España sigue siendo el país de la desmemoria. El pueblo que camina del genocidio franquista al silencio interminable ${ }^{1}$.

Sí, somos "el país de la desmemoria". Somos el país de la negación, el olvido, la banalidad del mal, la ignorancia, la invisibilidad y sobre todo de la (des)memoria.

$\mathrm{Y}$ en lo que se refiere a la represión de la masonería, conviene tener en cuenta, por ejemplo, lo que se repite machaconamente años tras año, en el Senado de España, cuando se celebra el 27 de enero el "Día Oficial de la Memoria del Holocausto y la Prevención de los Crímenes contra la Humanidad".

Durante quince años consecutivos (y se dice pronto) el Senado se olvidó de la represión que sufrieron los masones en la guerra civil y durante el franquismo, hasta la muerte de Franco en 1975.

Solo el testimonio del presidente de la Federación de Comunidades Judías de España, Isaac Qerub, hablando en nombre de quienes sufrieron lo impensable, incluyó en su memorial a los masones:

Hoy, un año más, amparados por la solemnidad de este acto, nos reunimos aquí en el Senado, símbolo de la soberanía popular, para recordar a los seis millones de judíos,

\footnotetext{
${ }^{1}$ Juan Miguel, Baquero, El país de la desmemoria. del genocidio franquista al silencio interminable (Barcelona, Roca Editorial, 2019).
} 
y las demás víctimas de la barbarie nazi, como los discapacitados, los gitanos, los disidentes políticos, los republicanos españoles, los homosexuales o los masones².

Sin embargo, a diferencia del Senado, otras instituciones, como el Parlamento de las Islas Baleares, y recientemente también el de Galicia, han invitado a representantes de la Gran Logia de España en sus actos conmemorativos. Y, el Museo del Holocausto de Estados Unidos rememora que la represión de los masones en la Alemania nazi se inició muy temprano. Recuerda que ya en 1934 se confiscaron sus bienes, sus bibliotecas, sus archivos y se prohibieron las logias masónicas al ser consideradas incompatibles con el Estado alemán.

Una sección especial de las SS se ocupó de modo específico de la represión de la Masonería. Los masones igual que el resto de las víctimas del genocidio fueron eliminados en los campos de exterminio. Los nazis persiguieron todas las organizaciones masónicas en los países ocupados, incautando su documentación, como sucedió en la España franquista.

Entre los archivos incautados figuraban los del Grande Oriente Español, depositados en la sede del Gran Oriente de Francia, en París, que le fueron enviados a Franco para que completara la represión de la masonería española, cuando los nazis ocuparon la capital de Francia.

Este acto de desmemoria que se repite cada año en el Senado sería algo incomprensible (desde luego es injustificable) si no fuera porque se trata de una prueba más que demuestra que aquí en España no hemos resuelto la cuestión de la memoria histórica, porque, como digo, no tenemos memoria.

Lo que dice Heródoto de la tarea del historiador

Quizá sea oportuno traer a colación lo que dice Heródoto de Halicarnaso en el primer tomo de su obra magistral dedicado a la Historia, hablando de su propio trabajo como historiador:

Ésta es la exposición del resultado de las investigaciones [historiê] de Heródoto de Halicarnaso para evitar que, con el tiempo, los hechos humanos queden en el olvido y que las notables y singulares empresas realizadas, respectivamente, por griegos y bárbaros y, en especial, el motivo de su mutuo enfrentamiento, queden sin realce" 3 . Heródoto, Historia I, 1

Como vemos Heródoto nos propone la tarea de hacer historia precisamente "para evitar que, con el tiempo los hechos humanos queden en el olvido", propuesta particularmente oportuna cuando hablamos del "país de la desmemoria", y yo añadiría de la negación y el ocultamiento de la historia.

\footnotetext{
${ }^{2}$ Isaac Querub en la celebración del Día Oficial de la Memoria del Holocausto y la Prevención de los Crímenes contra la Humanidad, pronunciado en el Senado, el 27 de enero de 2019, https://www.youtube.com/watch?v=oq0WZ9ayV0g

${ }^{3}$ La cita de Heródoto procede Carlos García Gual, Grecia para todos (Barcelona: Espasa, 2019), 139.
} 


\section{El deber de memoria}

Debemos recordar que desde el mismo inicio de la guerra civil fueron fusilados los masones en el bando rebelde, por el simple hecho de serlo y sin necesidad de ninguna prueba, ni de ninguna otra acusación. Incluso, se dio el caso de que fueron fusilados algunos que no eran masones pero que habían sido acusados de serlo ${ }^{4}$.

Sabemos que la violencia antimasónica se circunscribe en el clima de violencia generalizada que habían previsto los conspiradores cuando preparaban el golpe militar. La persecución de los masones era uno de los objetivos principales del bando rebelde. El coronel Marcelino Gavilán Almuzara, gobernador civil de Burgos, el 18 de julio de 1936, decía: "Hay que echar al carajo toda esta monserga de derechos del hombre, humanismo, filantropía y demás tópicos masónicos" $"$.

Por su parte, el teniente coronel Yagüe en unas Directivas para Marruecos planteaba que había que

conferir el mando del orden público y seguridad en las ciudades a elementos de Falange; detener a las autoridades civiles españolas que sean sospechosas; clausurar todos los locales de reuniones públicas, tales como centrales sindicales, logias masónicas, sedes de partidos, casas del pueblo, ateneos... y especialmente eliminar los elementos izquierdistas: comunistas, anarquistas, sindicalistas, masones, etc.. ${ }^{6}$.

Las primeras detenciones fueron ordenadas por los militares y llevadas a cabo por milicias falangistas, casa por casa y pueblo por pueblo, ejecutando a las víctimas en las tapias de las cárceles y en las de los cementerios. Pero fueron tan numerosas y descontroladas que Mola envió un telegrama al Estado Mayor de la VII división, el 22 de agosto de 1936, prohibiendo dichas actuaciones ${ }^{7}$.

Pero la responsabilidad de estos desmanes vino de los militares golpistas que en sus proclamas habían instigado al total exterminio del enemigo. Falangistas, requetés y otros sectores de la derecha fueron los instrumentos de esta salvaje represión.

\footnotetext{
${ }^{4}$ José Antonio, Ferrer Benimeli, La Masonería en Aragón (Zaragoza: Librería General, 1979), vol III, 117-194. Y también Ferrer Benimeli, Masonería española contemporánea (Madrid: Siglo XXI de España editores, 1980), vol. 2, 146-147.

${ }^{5}$ Santiago Vega Sombría, De la esperanza a la persecución. La represión franquista en la provincia de Segovia (Barcelona: Crítica, 1985), 68.

${ }^{6}$ Francisco Espinosa, "Julio de 1936. Golpe militar y plan de exterminio", en Morir, matar, sobrevivir. La violencia en la dictadura de Franco, coord. Julián Casanova (Barcelona: Crítica, 2002), 61.

${ }^{7}$ En el telegrama se dice: "Prohíban de forma terminante que falangistas o fuerzas similares practiquen detenciones sin orden escrita y cometan actos de violencia, pues estoy dispuesto a castigar severamente, en juicio sumarísimo, los crímenes que cometan, llegando incluso a la disolución de las agrupaciones que los realicen".
} 


\section{Cruzada antimasónica}

El doloroso "Vía Crucis" que padecieron los masones se agravó por el propio concepto de Cruzada, que implicaba la apelación a una brutal actuación de rancias reminiscencias medievales. Don Marcelino Olaechea, obispo de Pamplona y Don Rigoberto Doménech, arzobispo de Zaragoza, definían la guerra civil española como una auténtica cruzada religiosa, el 26 de agosto de 1936. Y don Tomás Muñiz Pablos, arzobispo de Santiago, declaraba el 31 de agosto:

La guerra "levantada” contra los enemigos de España es "patriótica sí, muy patriótica, pero fundamentalmente una Cruzada religiosa, del mismo tipo que las Cruzadas de la Edad media, pues ahora como entonces se lucha por la fe de Cristo y por la libertad de los pueblos. ¡Dios lo quiere! ¡Santiago y cierra España! ${ }^{8}$

El padre Constantino Bayle escribe en la revista Razón y Fe, en 1937, un artículo titulado "El espíritu de Falange Española ¿es católico?”, en el que afirma, entre otras cosas:

Si por fascistas se entienden a los que propugnan un Gobierno que dé al traste con la farsa del parlamentarismo y del sufragio universal; que ahogue los sindicatos y partidos de la revolución, cuevas de bandoleros; que abomine de la democracia al uso, disfraz de vividores y camisa de fuerza para el pueblo incauto; que descuaje la envenenada semilla judeo-masónica, entonces sí: el Alzamiento Nacional, el Gobierno de Franco, toda la España cristiana son fascistas ${ }^{9}$.

Pero de todos los documentos publicados durante la guerra, destaca, sin duda, la tristemente famosa Carta Colectiva del Episcopado Español, que fue publicada el 1 de julio de 1937, a sugerencia de Franco, con la idea de lograr el apoyo del Vaticano.

La carta define la guerra como cruzada de liberación, fue redactada por el cardenal Gomá, con el beneplácito de la Secretaría de Estado del Vaticano, y fue firmada por todos los obispos españoles, a excepción de cinco (los obispos de Orihuela, Menorca, Vitoria, Tarragona, y el cardenal Segura).

Las cinco firmas que faltaron no mermaron la eficacia del documento episcopal, que permitió a Franco, en declaraciones realizadas al periódico “L’Echo de París, el 16 de

\footnotetext{
${ }^{8}$ Casanova, La Iglesia de Franco (Barcelona: Crítica, 2005), 78; y Alfonso Álvarez Bolado, Para ganar la guerra, para ganar la paz. Iglesia y guerra civil: 1936-1939 (Madrid: Universidad Pontificia de Comillas, 1995), 55-56.

${ }^{9}$ Constantino Bayle, “El espíritu de Falange española ¿es católico?”, Razón y Fe 112 (1937): 236. Citado por Juan María Laboa, Iglesia e intolerancia: la guerra civil (Madrid: Sociedad de Educación Atenas, 1987), 203219, y en Casanova, La Iglesia de Franco, 85-86.
} 
noviembre de 1937, manifestar que los objetivos de la guerra civil eran "nacionales" y "religiosos".

Nuestra guerra es una guerra religiosa. Nosotros, todos los que combatimos, cristianos o musulmanes, somos soldados de Dios y no luchamos contra los hombres, sino contra el ateísmo y el materialismo, contra todo lo que rebaja la dignidad humana, que nosotros queremos elevar, purificar y ennoblecer ${ }^{10}$.

Franco fue un auténtico paladín de la cruzada antimasónica. La persecución de los masones - su particular "cruzada" - fue una de las mayores obsesiones del Caudillo. Ricardo de la Cierva asegura que

la convicción antimasónica se ha incorporado a Franco casi como una segunda naturaleza. Franco ha simplificado en la masonería todas las causas de la decadencia histórica y la degeneración política de España. La ha perseguido de forma implacable. Se ha creído cercado por ella. Ha transformado toda su vida en una cruzada antimasónica. No admitía, acerca del tema, ni de la evidente exageración con que ha interpretado el tema, disensión alguna [...]. Franco ha llegado a afirmar públicamente que la Cruzada se hizo contra la Enciclopedia ${ }^{11}$.

\section{La bestia masónica}

La guerra adquirió tintes de una dramática batalla contra los masones y la masonería, siempre atizada por los sectores eclesiásticos más ultras. En 1937, siguiendo el ejemplo de los obispos, en la revista de los Misioneros del Corazón de Jesús de Bilbao, se publican los diversos argumentos retóricos que justificaban el exterminio de los masones. Son los siguientes:

¿Qué es la masonería? Hay todavía algunos mentecatos que creen que la masonería es una sociedad de beneficencia y de progreso, para el fomento de la verdad y el ejercicio de la beneficencia. Es mentira.

La verdad es que la masonería es una sociedad de hombres sin religión, unidos por una organización misteriosa y por juramentos horribles, sujeta y esclavizada a la dirección oculta de jefes invisibles cuyo objeto es hacer guerra a la Iglesia y a la sociedad, y con pretexto de establecer la libertad, igualdad y fraternidad, resucitar en el mundo la impiedad y el paganismo.

Es una sociedad secreta. Deja, aunque con dificultad, que se descubra de ella el ritualismo, el aparato de sus iniciaciones, las ceremonias de los grados, con todas esas zarandajas de ojos vendados, pasos perdidos, salas enlutadas, puñales que relucen, calaveras, cruces, mandiles, bóvedas de espadas y demás misterios terroríficos y

\footnotetext{
${ }_{10}$ Juan José, Morales Ruiz, El discurso antimasónico en la guerra civil española (1936-1939) (Zaragoza: Departamento de Cultura y Turismo del Gobierno de Aragón, 2001), 130-133.

${ }^{11}$ Ricardo de La Cierva, Historia del franquismo (Barcelona: Planeta, 1976), 230.
} 
espantosos. Pero eso es lo exterior: detrás de todo esto está oculto el antro donde descansa la bestia masónica.

Detrás de estos testaferros que ocupan los grados hay otra parte más secreta de la masonería, donde se fraguan los planes, se conjura, se preparan las calumnias, las iniquidades, las revoluciones, los sacrilegios. Y aún detrás todavía está la tercera masonería, la cabeza de la bestia que nadie sabe quién es, porque se oculta a todo el mundo.

Todo el mundo se pregunta: ¿quién es el jefe principal de la masonería? ¿un hombre? ¿un pueblo? ¿un diablo? ¿los judíos? ¿los protestantes? ¿los anarquistas? ¿pero quiénes? ¿de quién es la mano oculta que lo dirige todo? ¡Y nadie da con ella! Basta esto para asegurar que la masonería es mala. El que obra mal odia la luz, como dijo el Maestro.

La masonería es una sociedad impía. En todas sus reuniones se blasfema contra Dios delante de todos, y en todos sus ritos se insulta al cristianismo, y en sus jueves santos se profana la religión cristiana (...)

No solo es impía ella, en sí, sino anticatólica. En el decreto masónico de la Asamblea general de las Logias francesas de 1876 decíase: "Nuestro objetivo es descristianizar al pueblo por todos los medios, pero especialmente estrangulando al catolicismo poco a poco y cada año con nuevas leyes contra el clero; dentro de pocos años con nuevas leyes contra el clero; dentro de pocos años y mediante la enseñanza laica tendremos una generación atea" (...)

La masonería es revolucionaria. Apenas hay revolución en toda la historia contemporánea en la que no haya tenido mucha participación la masonería, y muchas veces la dirección. Suya fue la gran Revolución Francesa que hizo de Francia un charco de sangre y de abominaciones. Suyas han sido en España la mayor parte de las revueltas y guerras civiles, y en especial la pérdida de nuestras colonias.

Suyo fue el Kulturkampf, la persecución más ignominiosa en Alemania contra el catolicismo, suyas las revoluciones italianas contra el Papado, suya la Semana Sangrienta de Barcelona, dirigida por su Ferrer, a quien tienen la insolencia y desvergüenza de defender y justificar, suya la revolución portuguesa, llena de asesinatos y de iniquidades, suyos los más de los movimientos revolucionarios de España, de donde quieren arrojar la monarquía para implantar la república.

La masonería se vale de medios inicuos. Juramentos horribles, secretos rigurosísimos, compromisos criminales, atentados públicos, calumnias viles, delaciones indignas, promesas falaces, asesinatos misteriosos, envenenamientos, amenazas, mentiras, ficciones, sobornos, suplantaciones, infidelidades, todos estos pecados constan en historias innegables.

Aunque fuesen falsos el cincuenta por ciento de los crímenes que se le atribuyen, todavía les queda bastante para horrorizar al mundo y llevar ventaja a las instituciones más abominables. Y la masonería queda impune porque tiene en los gobiernos muchos cómplices que le deben a ella el puesto, y que están en el poder por la masonería a la que están vendidos ${ }^{12}$.

\footnotetext{
${ }^{12}$ Rayos de Sol, núm. 94. El Mensajero del Corazón de Jesús, Bilbao, 1937. En Ferrer Benimeli, La Historia en sus textos. La Masonería española (Madrid: Ediciones Istmo, 1996), 149.
} 


\section{El restablecimiento de la Compañía de Jesús}

En el preámbulo del decreto por el que se restablecía la Compañía de Jesús, en mayo de 1938, se habla de las "logias enemigas" y se vuelve a manifestar el carácter católico del nuevo régimen que se va estableciendo en la zona ocupada por los nacionales:

Las fuerzas secretas de la Revolución, en su incesante trabajar por la destrucción de España, una vez más hicieron certero blanco de sus odios a la egregia y españolísima Compañía de Jesús, decretando su disolución en veintitrés de enero de mil novecientos treinta y dos, en disposición promulgada, según decía su preámbulo, para ejecución del artículo veintitrés de la Constitución, que, lejos de recoger los anhelos nacionales, sintetizaba, en forma de preceptos legales, los dictados de las Logias enemigas irreconciliables de la Gran Patria Española.

De este despertar glorioso de la Tradición española, forma parte principal el restablecimiento de la Compañía de Jesús en España, en la plenitud de su personalidad, y éste por varias razones.

En primer término, para reparar débilmente la injusticia contra ella perpetrada. En segundo lugar, porque el Estado Español reconoce y afirma la existencia de la Iglesia Católica como sociedad perfecta en plenitud de sus derechos y, por consiguiente, ha de reconocer también la personalidad jurídica de las Órdenes Religiosas canónicamente aprobadas, como lo está la Compañía de Jesús desde Paulo III y posteriormente por Pio VII y sus sucesores.

En tercer término, por ser una Orden eminentemente española y de gran sentido universal, que hace acto de presencia en el cenit del Imperio Español, participando intensamente en todas sus vicisitudes, por lo que, con infeliz coincidencia, caminan siempre juntos en la Historia las persecuciones contra ella y los procesos del desarrollo de la anti-España.

Y, finalmente, por su enorme aportación cultural, que tanto ha contribuido al engrandecimiento de nuestra Patria y a aumentar el tesoro científico de la Humanidad, por lo que Menéndez Pelayo calificó su persecución de "golpe mortífero para la cultura española y atentado brutal contra el saber y las letras humanas"13.

\section{Como los antiguos Cruzados}

El Papa Pio XII en el mensaje navideño de 1942, en plena Segunda Guerra Mundial, todavía hablaría de la necesidad de llevar a la práctica este espíritu belicoso cristiano:

El precepto de la hora presente no es el lamento, sino la acción [...] Conviene a los mejores y más selectos miembros de la Cristiandad, penetrados por un entusiasmo de cruzados, reunirse en espíritu de verdad, de justicia y de amor, al grito de "Dios lo quiere", dispuestos a servir, a sacrificarse, como los antiguos Cruzados ${ }^{14}$.

\footnotetext{
${ }^{13}$ Publicado en el BOE de 7 de mayo de 1938. Fernando Díaz Plaja, La guerra de España en sus documentos (Barcelona: Marte, 1969), 325-326.

${ }^{14}$ Pio XII, Radiomensaje de Navidad, 24 de diciembre de 1942.
} 


\section{Quema de libros}

De la persecución no se libraron ni los libros. Por ejemplo, mediante una circular de la Inspección de Primera Enseñanza de Logroño se ordenaba a los maestros que quemaran los libros "rojos", en presencia de los alcaldes:

Por acertada Orden de la Junta de Defensa Nacional de España se dispone que desaparezcan de todas las Bibliotecas las obras de carácter masónico, marxista o comunista, y que en las escuelas solamente se usen textos cuyo contenido responda a los sanos principios de la Religión y la Moral cristianas y que exalten con su ejemplo el patriotismo de los niños.

Esta Inspección hubiera querido hacer personalmente la depuración de las bibliotecas escolares y circulantes y la de los libros escolares de texto, pero en la imposibilidad material de hacerlo espera que todos los señores maestros quemarán inmediatamente, en presencia de los señores Alcaldes, cuantos libros se hallen en las condiciones precitadas, y cuando tengan dudas sobre ellos los retirarán del alcance de los niños y enviarán un ejemplar a esta Inspección para su estudio.

Una vez hecha la depuración remitirán un catálogo de la biblioteca y otro de los libros escolares de texto. Logroño, 7 de octubre de 1936. El Inspector: Anselmo Rodríguez ${ }^{15}$.

Este espíritu destructor fue impulsado desde algunas publicaciones falangistas, como por ejemplo Arriba España, en cuyo primer número - publicado el 1 de agosto de 1936-, se leía en primera página: "Camarada, tienes la obligación de perseguir al judaísmo, a la masonería, al marxismo y al separatismo. Destruye y quema sus periódicos, sus libros, sus revistas, sus propagandas" 16 .

\section{El primer bando antimasónico}

El primer bando antimasónico fue firmado por el general Dolla, el 15 de septiembre de 1936, en Santa Cruz de Tenerife. Un bando que tuvo el dudoso privilegio de ser el primer documento antimasónico de la guerra civil española. ${ }^{17}$ Veamos su articulado:

Don Ángel Dolla Lahoz Comandante General de Canarias ${ }^{18}$ :

Ordeno y mando:

\footnotetext{
${ }^{15}$ Boletín de Educación de la Provincia de Logroño 23 y 24 (septiembre-octubre de 1936).

${ }^{16}$ Rafael García Serrano, La gran esperanza. Nosotros, los falangistas (Barcelona: Planeta, 1983), 160.

${ }^{17}$ El bando fue publicado en la primera página del Boletín Oficial de la Provincia de Santa Cruz de Tenerife 125 (16 de octubre de 1936).

${ }^{18}$ El general Ángel Dolla Lahoz se sublevó en Zaragoza contra el gobierno de la República el 18 de julio de 1936. El 4 de septiembre de ese mismo año fue nombrado jefe de la Comandancia General de Canarias. Llega a Tenerife el domingo 13 de septiembre, tomando posesión de su cargo ese mismo día.
} 
Art. 1. Quedan declaradas fuera de la Ley la Masonería y las demás asociaciones de naturaleza secreta. Cualquier actividad referente a las mismas, con posterioridad a este Bando se considerará como delito de rebelión.

Art. 2. La recaudación y abono de cuotas por los interesados a sus mandatarios en favor de las asociaciones secretas serán consideradas como delito de auxilio para cometer la rebelión, independiente de la multa de cinco mil pesetas que se pueda imponer en vía Gobernativa.

Art. 3. Todos los documentos de identidad, acreditativos de recaudación de cuotas, correspondencia, emblemas, etc., deberán ser destruidos por sus poseedores en el plazo de tres días a partir de la publicación de este Bando, en la inteligencia de que una vez transcurrido dicho plazo, el encontrarse los mismos bien en la persona o en cualquier domicilio, será constitutivo de un delito de desobediencia grave, sancionado además gubernativamente con una multa hasta la cantidad de 10.000 pesetas.

Art. 4. Las obras de propaganda referente a las aludidas asociaciones se consideran incluidas en el art. $7^{\circ}$ del Bando del 3 de septiembre pasado, debiendo por tanto ser destruidas por sus poseedores en el plazo de tres días que en el mismo se fija.

Art. 5. Los inmuebles propiedad de las aludidas asociaciones serán ocupados por los agentes de la autoridad y destinados a los servicios que se fijen; los alquilados serán desalojados en igual forma y puestos a disposición de sus dueños respectivos.

Santa Cruz de Tenerife, 15 de septiembre de 1936. Ángel Dolla

El delito de masonería se consideraba como un delito de rebelión y se castigaba con la pena de muerte, sin necesidad de someterlo a un consejo de guerra.

\section{Un editorial del periódico "Amanecer"}

Siguiendo con la cronología de la represión de la masonería, destacamos un editorial publicado en el periódico falangista zaragozano "Amanecer" el 19 de septiembre de 1936, en el que, entre otras cosas se decía:

Sería prolija la enumeración de la obra destructora, cruel, verdaderamente satánica de la Masonería, en relación con España. La historia de los últimos cinco años no es sino una ininterrumpida sucesión de crímenes, de atropellos, de persecuciones incesantes contra España y contra todo lo que España representa.

Persecución que se tramaba en las logias masónicas a las que pertenecían los gobernantes y las altas autoridades del Estado, los diputados, los gobernadores y los caciquillos de las capitales provincianas.

La Masonería había tramado un tinglado infame a la sombra de la protección oficial, del que salían las grandes y pequeñas persecuciones, los atentados, los crímenes, las injurias, las calumnias, la saña, el rencor y el odio contra España, contra la tradición y el sentido de España.

Todas las leyes persecutorias y aniquiladoras que salieron de las Constituyentes fueron obra de la Masonería en combinación con los demás poderes ocultos que han tenido a España destrozada, desfigurada, convertida en guiñapo del mundo. 
¿No es, por tanto, la Masonería una sociedad delincuente? ¿No son delincuentes los masones? ¿No es delito ser masón? Delito es y gran delito nacional de lesa Patria, de lesa sociedad. Y ahora manda la Patria, manda la Nación.

Y no hay más que un sólo Código, el Código Nacional, el Código del sentir nacional, de la reintegración nacional, del aniquilamiento de cuanto no sea nacional. La Nación, la Patria, España por encima de todo y cuanto a España se oponga hay que destruirlo sin contemplaciones.

Y la Masonería se opone a España, se ha opuesto con todo su satánico poder (...) La Masonería se opone a España; pues hay que acabar con la Masonería y con los masones $^{19}$.

\section{Recogida de material masónico}

La represión de los masones continuaría a medida que se iba ocupando el resto del territorio español. Y cuando se plantee la depuración de responsabilidades políticas, Franco ordenará la recogida de "material masónico" en lugar de su destrucción, como se había ordenado en el bando del comandante general de Canarias. La orden se transmite desde el Estado Mayor del Cuartel del Generalísimo, por telegrama, y dice lo siguiente:

Cuartel General del Generalísimo. Estado Mayor. Telegrama postal. El Generalísimo al General Jefe de Seguridad Interior, Orden Público e Inspección de Fronteras y Gobernador General del Estado:

Sírvase disponer que por las Autoridades dependientes de V. E. Se proceda a la recuperación de cuantos documentos, emblemas, insignias, y demás objetos relacionados con la Masonería, que se hallen en poder de particulares, o centros políticos y sociales.

Los elementos recuperados se enviarán bajo inventario a la Delegación Nacional de Servicios Especiales en mi Secretaría Particular. Salamanca. Transmítase de Orden de S. E. El General Jefe de Estado Mayor, Francisco Martín Moreno. El Coronel de Estado Mayor Jefe de la Sección. Burgos, 11 de enero de $1938^{20}$.

\section{Supresión de símbolos masónicos en los cementerios ${ }^{21}$}

La derogación de la ley del año 32 sobre cementerios civiles supondrá la supresión de toda simbología masónica en diciembre de 1938. El preámbulo de la ley anticipa el programa represivo que Franco va a desarrollar a partir de la victoria del 1 de abril, para anular y contrarrestar las medidas sociales llevadas a cabo por la República. En él se dice:

\footnotetext{
19 Morales Ruiz, Palabras Asesinas. El discurso antimasónico en la guerra civil española (Oviedo, Masonica.es, 2017), 171.

${ }^{20}$ Ferrer Benimeli, La Historia en sus textos, 204-205.

${ }^{21}$ La Ley firmada por Franco en Burgos el 10 de diciembre de 1938 (III Año Triunfal) fue publicada en el $B O E$ 175 (20 de diciembre de 1938): 30-40.
} 
La legislación española de acuerdo con el espíritu de la Iglesia conservó los Cementerios parroquiales con carácter netamente confesional, ordenando la construcción de cementerios civiles, con absoluta separación de los católicos, para enterar en aquellos los cadáveres de los que hubiesen muerto fuera del seno de la Iglesia.

El espíritu sectario que alentaba en toda la legislación de la república de 1931, hubo de manifestarse también en esta materia de Cementerios y por eso en la Ley de 30 de enero de 1932, se mandó a las Autoridades derribar las tapias que separaban los cementerios católicos de los civiles y se autorizó a los Municipios para que se incautaran los cementerios parroquiales, atropellando el sagrado derecho de la propiedad de la Iglesia sobre sus recintos, considerados por el pueblo como algo tan religioso y tan sagrado que vulgarmente se les llama Camposantos y hasta se prohibió el enterramiento religioso de toda persona mayor de 20 años que no hubiera manifestado de modo expreso su voluntad, vejamen gravísimo a la inmensa mayoría del pueblo español, que profesa la Religión católica, y disposición tan sectaria que acaso no tenga precedente en el derecho de ningún Estado culto.

En el artículo $1^{\circ}$ se deroga "la Ley de 30 de enero de 1932 sobre Cementerios Municipales y cuantas disposiciones complementarias se hubieran dictado para su ejecución". Mediante el artículo $2^{\circ}$ se indica que "las Autoridades Municipales restablecerán, en el plazo de dos meses, a contar desde la vigencia de esta Ley, las antiguas tapias, que siempre separaron los cementerios civiles de los católicos".

En el artículo $3^{\circ}$ "se reconoce y se devuelve a la Iglesia y a las Parroquias respectivas la propiedad de los Cementerios parroquiales y de cualquiera otros Cementerios de que se hubiesen incautado los Municipios, a tenor del artículo primero de la Ley que se deroga".

En el artículo $4^{\circ}$ se declara que "la jurisdicción en los Cementerios católicos corresponde a la Autoridad Eclesiástica, cualquiera que sea la persona o entidad a los que competa la administración de aquellos".

En el artículo $5^{\circ}$ se afirma que "la jurisdicción de los Cementerios civiles compete a la Autoridad civil". El artículo $6^{\circ}$ se refiere a exclusivamente al tema de la supresión de los símbolos masónicos. En él se ordena que

en el término de dos meses, a contar desde la vigencia de la Ley, los dueños, administradores o encargados, de panteones, sepulturas, nichos o cualquier clase de monumentos funerarios, están obligados, bajo su responsabilidad, a hacer desaparecer de los mismos, todas las inscripciones y símbolos de sectas masónicas y cualquiera otras que de algún modo sean hostiles u ofensivas a la Religión Católica o a la moral cristiana. Si no lo hicieran, lo hará la entidad a quien competa la administración del Cementerio respectivo, que se resarcirá de los gastos reclamando su importe a los obligados. 


\section{Denuncia y delación}

Uno de los rasgos más característicos del territorio sublevado es la enorme presión a la que estaba sometida su población" . "Puedes perdonar lo que te hicieron a ti; pero no eres nadie para hurtar a la justicia ningún enemigo de la Patria"23.

El hecho de no denunciar a nadie era ya un motivo de sospecha. Para no recaer en él, mucha gente daba un buen número de nombres, facilitando la tarea represiva de los rebeldes, obsesionados en recopilar información para masacrar al enemigo y eliminar hasta el más mínimo vestigio del sistema republicano en la "zona liberada" 24 .

\section{Un programa represivo aterrador}

En la portada del periódico falangista “Águilas”, del jueves 27 de mayo de 1937 (año II, núm. 148, Cádiz) página 1, figura debajo de la mancheta un texto que me parece que resume, como pocos el programa represivo de los franquistas: "Crearemos campos de concentración para vagos y maleantes políticos; para masones y judíos; para los enemigos de la Patria, el Pan y la Justicia. En territorio nacional no puede quedar ni un judío, ni un masón, ni un rojo".

Me parece que ese "no puede quedar" anuncia y anticipa bien a las claras la vocación exterminadora del enemigo. Y explica el altísimo número de ejecutados y desaparecidos, de los que lamentablemente, se desconoce dónde fueron fusilados, y en muchos casos todavía hoy, sus familiares no saben dónde están sus cuerpos sepultados.

Conviene que quede claro que, aunque el Senado lo olvide cada año en sus conmemoraciones, hubo masones españoles en los campos de concentración y en las cárceles franquistas, cuando no fueron asesinados. Muy pocos pudieron librarse de la represión o la muerte.

\section{Terror en los campos de Franco}

Recordemos que el programa represivo que, como hemos visto, había sido anunciado en el periódico falangista gaditano, incluso se hizo realidad desde el primer día de la guerra, en la España franquista.

Como explica José Ramón González ${ }^{25}$, y se puede comprobar en la documentación depositada entre otros en el Archivo General Militar de Ávila, en el Archivo General Militar

\footnotetext{
${ }^{22}$ Gil Vico, "Ideología y represión: La Causa General. Evolución histórica de un mecanismo jurídico-político del régimen franquista", Revista de Estudios Políticos (Nueva Época) 101 (julio-septiembre 1998).

${ }^{23}$ Publicado en El Diario Montañés (20 de octubre de 1937).

${ }^{24}$ Alberto Reig Tapia, Ideología e Historia: Sobre la represión franquista y la guerra civil (Madrid: Akal, 1986), 146

${ }^{25}$ José Ramón González, "Represión, esclavitud y exclusión. un análisis a escala de la violencia franquista", Entelequia. Revista Interdisciplinar 7 (septiembre 2008): 155.
} 
de Guadalajara y también en menor medida, en el Archivo General Militar de Segovia y en otros registros civiles,

ya desde los primeros días de la guerra y a medida que el Ejército sublevado iba ocupando nuevos territorios, se fue generando una masa ingente y continua de prisioneros de guerra y detenidos políticos.

Ello provocó un "problema" de acumulación de aprehendidos al que los militares franquistas respondieron con el progresivo "acondicionamiento" de multitud de centros de detención arbitrarios. Dichos establecimientos poseían una serie de peculiaridades que les diferenciaban de las instituciones penitenciarias tradicionales y que anticipaban, al menos parcialmente, los campos de concentración franquistas. Tales lugares poseían carácter provisional y dependían directamente de la jurisdicción militar; asimismo, los prisioneros allí confinados no lo estaban por una sanción jurídica concreta, sino por de forma preventiva y a la espera de que se dilucidaran sus "responsabilidades".

Además, la naturaleza ilegal de estos centros se acentuaba aún más por la procedencia de los detenidos. Es cierto que muchos eran prisioneros de guerra, pero también había recluidos por cuestiones ideológicas o por simples diferencias personales.

Tal iniquidad sobrepasó el mero confinamiento y control social de los retenidos, y se consolidó a través del empleo desmedido de la violencia -asesinatos, torturas, violaciones, escarnio público-, y su uso con fines ejemplarizantes y desmoralizadores.

En efecto, en la zona nacional se instalaron campos de concentración entre 1936 y 1947, algunos con carácter estable y otros muchos provisionales, dependiendo de la evolución de la contienda. Todos ellos estaban coordinados por el llamado "Servicio de Colonias Penitenciarias Militarizadas" (SCPM), organismo creado en septiembre de 1939.

Los campos de concentración fueron uno de los instrumentos más brutales de la represión franquista ${ }^{26}$. Terminaban en estos campos de concentración desde prisioneros republicanos del Ejército Popular, las Fuerzas aéreas y la Marina de guerra, hasta disidentes políticos, homosexuales, gitanos, masones y presos comunes. Los campos se caracterizaron por la explotación laboral de los prisioneros, organizados en batallones de trabajadores.

Según Javier Rodrigo cerca de medio millón de prisioneros pasaron por los campos de concentración entre 1936 y 1942. El primer campo de concentración fue creado por Francisco Franco poco después del comienzo de la guerra civil, el 20 de julio de 1936, y estuvo localizado en el castillo del monte Hacho de $\mathrm{Ceuta}^{27}$.

\footnotetext{
${ }^{26}$ Carlos Hernández de Miguel, “Terror en los campos de Franco”, El País, 8 de marzo de 2019, 57-63.

27 Javier Rodrigo, Cautivos: campos de concentración en la España franquista, 1936-1947 (Barcelona: Crítica, 2005).
} 
Miembros de la Gestapo se señalaron como los organizadores de la red de campos de concentración franquistas. Se inspiraron en los campos de concentración de la propia Alemania nazi.

De aquellos oficiales nazis destacó Paul Winzer, jefe de la Gestapo en España, y jefe durante algún tiempo del Campo de concentración de Miranda de Ebro. Incluso se cree que Winzer fue el verdadero autor de toda la organización de los campos de concentración franquistas $^{28}$.

En 1938 los campos de concentración franquistas albergaban a más de 170000 prisioneros. Al final de la contienda, en 1939 la cifra de población reclusa oscilaba entre las 367000 y las 500000 personas. Desde 1940 el supervisor de todos estos campos fue el general Camilo Alonso Vega.

La principal función de los campos era la de retener a tantos prisioneros de guerra republicanos como fuera posible, pero todos aquellos que fueran calificados de "irrecuperables" eran automáticamente ejecutados. Encargados de la administración de los campos habían sido víctimas en la zona republicana, y por este motivo actuaron con una manifiesta voluntad de venganza con los presos.

Algunos altos dirigentes, como Máximo Cuervo Radigales, Director General de Prisiones, y Lorenzo Martínez Fuset, jefe del Cuerpo Jurídico Militar, y estrecho colaborador de Franco, contribuyeron en crear este clima de inhumana represión.

Todavía, en 1946, diez años después del comienzo de la Guerra civil, estaban operativos 137 campos de trabajo y tres campos de concentración, en los que estaban detenidos unos 30.000 prisioneros políticos. El último campo de concentración en cerrar fue el de Miranda de Ebro, que fue clausurado en enero de 1947.

\section{Recogida de material masónico}

La represión de los masones continuó a medida que se iba ocupando el territorio español. Y cuando se plantea la depuración de responsabilidades políticas, Franco ordena la recogida de "material masónico" en lugar de su destrucción, como se había ordenado en el bando del comandante general de Canarias. La orden se transmite desde el Estado Mayor del Cuartel del Generalísimo ${ }^{29}$, por telegrama, y dice lo siguiente:

Cuartel General del Generalísimo. Estado Mayor. Telegrama postal. El Generalísimo al General Jefe de Seguridad Interior, Orden Público e Inspección de Fronteras y Gobernador General del Estado:

Sírvase disponer que por las Autoridades dependientes de V. E. Se proceda a la recuperación de cuantos documentos, emblemas, insignias, y demás objetos

\footnotetext{
${ }^{28}$ María de los Ángeles Egido León, Los Campos de Concentración Franquistas en el Contexto Europeo (Madrid: Marcial Pons, 2005).

${ }^{29}$ Ferrer Benimeli, La Historia en sus textos, 204-205.
} 
relacionados con la Masonería, que se hallen en poder de particulares, o centros políticos y sociales. Los elementos recuperados se enviarán bajo inventario a la Delegación Nacional de Servicios Especiales en mi Secretaría Particular. Salamanca. Transmítase de Orden de S. E. El General Jefe de Estado Mayor, Francisco Martín Moreno. El Coronel de Estado Mayor Jefe de la Sección. Burgos, 11 de enero de 1938.

\section{Alusiones antisemitas en un discurso del general Yagüe}

También conviene recordar algunas alusiones antisemitas en la ideología del bando franquista, sobre todo entre los jerarcas falangistas de máximo nivel. Y por supuesto en los discursos de Franco, como por ejemplo el Discurso de la Victoria, sobre el que nos detendremos más adelante.

Ahora, veamos el discurso del General Yagüe, pronunciado en el Teatro Principal de Burgos, el martes 19 de abril de $1938^{30}$, con ocasión del primer aniversario del Decreto de la Unificación. El general Yagüe, junto a una llamada a la reconciliación y el perdón añadió algunos elementos antisemitas, muy amenazadores por venir de quién venían. Dirigiéndose "a los poderosos con alma de judíos", dijo:

En la nueva España no habrá zánganos ni convidados. No los ha admitido nunca la Falange, pero ahora mucho menos. Seria criminal que permitiese que, del cuerpo extenuado, de la doliente España se alimentase parásitos aumentando sus dolores y prolongando la larga convalecencia que va a tener nuestra Patria por haber prodigado generosamente su sangre.

La guerra se acaba. Ni zánganos ni convidados, trabajadores todos. Todos al trabajo y pronto, señores. La guerra terminara pronto y entonces todos al trabajo. Todos con sus necesidades materiales atendidas.

Acaso tendrán que ceder algo de sus caudales los poderosos, pero lo han de hacer si son bien nacidos, con gusto, pensando solamente que si los rojos hubieses triunfado hubieses perdido todo, pues los españoles que están en la zona roja han perdido toda su hacienda, no es mucho pedir a estos señores que den un poco de lo que tienen para que lo disfruten los que a costa de su sangre les han defendido sus vidas y su hacienda (gran ovación).

Malos tiempos les auguro a los poderosos con alma de judíos. Habrá algunos, no lo dudo, con alma y con sangre de judío, que regateen esta acción social, que regateen esta justicia social, pero ¡Malos tiempo les aseguro a los adoradores del becerro de oro!

Les aconsejo noblemente que se vayan (gran ovación) que se lleven sus onzas, y sus alhajas y sus rentas, para nada nos servirán pero que también se lleven sus mañas, ¡sus consejos y sus almas encanijadas, que nos dejen tranquilos! Este es el primer punto fundamental en que se ha de asentar la nueva España: Justicia social amplia y generosa.

\footnotetext{
${ }^{30}$ Diario de Burgos, 19 de abril de 1938.
} 


\section{Una apelación constante a la sangre de los que cayeron por la Patria}

Al final de la guerra desde Radio Nacional de España se repetía insistentemente la siguiente consigna (que también se publicaba en los periódicos): "La paz no es un recurso cómodo y cobarde frente a la historia; la sangre de los que cayeron por la Patria no consiente el olvido, la esterilidad ni la traición" 31.

\section{En el 80 aniversario de la Ley de Responsabilidades Políticas}

El 13 de febrero de 1939, poco antes de finalizar la Guerra Civil Española, se publicó en el Boletín Oficial del Estado la Ley de 9 de febrero de 1939 de Responsabilidades Políticas. El objetivo de la ley fue descrito de una forma muy elocuente en su preámbulo:

liquidar las culpas [...] contraídas por quienes contribuyeron con actos $\mathrm{u}$ omisiones graves a forjar la subversión roja, a mantenerla viva durante más de dos años y a entorpecer el triunfo, providencial e históricamente ineludible, del Movimiento Nacional. Y también la magnitud intencional y las consecuencias materiales de los agravios inferidos a España son tales que impiden que el castigo y la reparación alcancen unas dimensiones proporcionadas.

La Ley declaraba retroactivamente la responsabilidad política de todas las personas que, entre octubre de 1934 y julio de 1936, «contribuyeron a crear o a agravar la subversión de todo orden de que se hizo víctima a España» y de todos aquellos que, durante la guerra, se hubieran "opuesto al Movimiento Nacional con actos concretos o con pasividad grave".

Además, la ley declaró que todos los partidos y organizaciones contrarios a la ideología de la naciente dictadura (incluida la masonería) quedaban ilegalizados y todos sus bienes requisados. La entrada en vigor de la ley dotó de base jurídica a la represión del final de la guerra y de la posguerra.

A través de un sistema de tribunales, en cuya cúspide se encontraba el Tribunal Nacional de Responsabilidades Políticas, se juzgó a miles de personas a las que se les acusó de lo anteriormente expuesto. Las sanciones preveían penas muy diversas, como la inhabilitación al ejercicio de su profesión o actividad, el destierro, la pérdida de sus bienes o, incluso, la pérdida de la nacionalidad española. La ley se reformó en 1942 y se mantuvo activa hasta la entrada en vigor del Decreto-ley 10/1969, de 31 de marzo, por el que se declara la prescripción de todos los delitos cometidos con anterioridad al 1 de abril de $1939^{32}$.

\footnotetext{
${ }^{31}$ La Vanguardia Española, 17 de julio de 1939.

32 El Centro Documental de la Memoria Histórica (Salamanca) conserva los expedientes producidos por los Tribunales Nacional de Responsabilidades Políticas y el Regional de Madrid, los cuales se pueden consultar en el Portal de Víctimas de la Guerra Civil de PARES: https://bit.ly/1IJKpaO
} 


\section{Algunos de los artículos de la Ley de Responsabilidades Políticas}

En el Artículo $2^{\circ}$ de la Ley de responsabilidades políticas (9 de febrero de 1939) entre un largo de listado de partidos políticos y agrupaciones se declaran fuera de la ley todas las logias masónicas. Por ello, y como se dispone en el artículo $3^{\circ}$ (los masones) "sufrirán la pérdida absoluta de sus derechos de toda clase y la pérdida total de sus bienes. Estos pasarán íntegramente a ser propiedad del Estado", quedando "confirmadas las incautaciones llevadas a cabo" (con anterioridad).

En el artículo $4^{\circ}$ se manifiesta que "en virtud de lo dispuesto en el artículo 1, quedan incursos en responsabilidad política y sujetos a las sanciones que se les impongan en los procedimientos que contra ellos se sigan, las personas individuales que se hallen comprendidas en alguno de los casos siguientes: (...) h) Pertenecer o haber pertenecido a la Masonería, con excepción solamente de los que hayan salido de la secta antes del dieciocho de julio de mil novecientos treinta y seis por baja voluntaria por haber roto explícitamente con ella o por expulsión de la misma fundada en haber actuado en contra de los principios en que se inspira o de los fines que persigue".

$\mathrm{Y}$ en el artículo $7^{\circ}$ se dice:

Se tendrá en cuenta para agravar la responsabilidad del inculpado su consideración social, cultural, administrativa o política cuando por ella pueda ser estimado como elemento director o prestigioso en la vida nacional, provincial o local, dentro de su respectiva actividad.

En el caso h) del artículo $4^{\circ}$ se apreciarán, asimismo, como circunstancias agravantes el haber obtenido en la masonería alguno de los grados dieciocho al treinta y tres, ambos inclusive, y el haber tomado parte en las Asambleas de la Asociación Masónica Internacional y similares o en las Asambleas Nacionales del Gran Oriente Español, de la Gran Logia Española o de otras cualesquiera organizaciones masónicas residentes en España ${ }^{33}$.

\section{Se colapsaron los Tribunales y los Juzgados Especiales}

Con la Ley de Responsabilidades Políticas se inició la apertura de tal número de expedientes que enseguida se colapsaron los 18 Tribunales especiales y los 61 Juzgados establecidos a tal fin.

Lo que provocó que de los 125.286 expedientes (de responsabilidades políticas) abiertos a primero de octubre de 1941, sólo se hubieran resuelto 38.055.

El resto de los expedientes incoados (87.231) estaban tramitándose o seguían pendientes de sentencia. De hecho, un total de más de 300.000 personas sufrieron procesos de depuración, una tarea que no finalizó hasta 1943.

\footnotetext{
${ }^{33}$ BOE 44, 13 de febrero de 1939.
} 


\section{Discurso de Franco con motivo del Desfile de la Victoria}

Yo quisiera, españoles, que la unidad sagrada que alienta en vuestro común entusiasmo, y en el fervor por la obra de nuestros combatientes, no decaiga jamás; ha sido la base de nuestra Victoria, y en ella se asienta el edificio de la nueva España. Yo no puedo ocultaros en este día los peligros que todavía acechan a nuestra Patria.

Terminó el frente de la guerra, pero sigue la lucha en otro campo. La Victoria se malograría si no continuásemos con la tensión y la inquietud de los días heroicos, si dejásemos en libertad de acción a los eternos disidentes, a los rencorosos, a los egoístas, a los defensores de una economía liberal que facilitaba la explotación de los débiles por los mejor dotados.

No nos hagamos ilusiones: el espíritu judaico que permitía la alianza del gran capital con el marxismo, que sabe tanto de pactos con la revolución antiespañola, no se extirpa en un día, y aletea en el fondo de muchas conciencias. Mucha ha sido la sangre derramada y mucho ha costado a las madres españolas nuestra Santa Cruzada para que permitamos que la Victoria pueda malograrse por los agentes extranjeros infiltrados en las Empresas o por el torpe murmurar de gentes mezquinas y sin horizontes.

Hacemos una España para todos: vengan a nuestro campo los que arrepentidos de corazón quieran colaborar a su grandeza; pero si ayer pecaron, no esperen les demos el espaldarazo mientras no se hayan redimido con sus obras.

Para esta gran etapa de la reconstrucción de España necesitamos que nadie piense volver a la normalidad anterior; nuestra normalidad no son los casinos ni los pequeños grupos, ni los afanes parciales. Nuestra normalidad es el trabajo abnegado y duro de cada día para hacer una Patria nueva y grande de verdad. (...)

Pero para coronar nuestra gran obra necesitamos que a la Victoria militar acompañe la política; no basta ordenar la unidad sagrada, hace falta trabajarla, llevar la doctrina y las nuevas consignas a todos los lugares, que vosotros seáis los colaboradores de la nueva empresa, de la que son fuerzas de choque la juventud heroica que en los frentes de batalla y en las cárceles sombrías recogieron de labios de tantos héroes su último ARRIBA ESPAÑA. Esta es la misión de nuestro Movimiento ${ }^{34}$.

\section{Ley de Represión de la Masonería y el Comunismo}

El 1 de marzo de 1940 se promulga la Ley de Represión de la Masonería y el Comunismo ${ }^{35}$ que se hacía extensible también a "los sembradores de ideas disolventes contra la religión, la Patria, sus instituciones fundamentales, la armonía social, y etc.”.

\footnotetext{
${ }^{34} A B C, 19$ de mayo de 1939.

${ }^{35}$ Publicada en el Boletín Oficial del Estado 62, el 2 de marzo de 1940. Morales Ruiz, La publicación de la Ley de Represión de la Masonería en la prensa de la España de postguerra (1940) (Zaragoza: Institución Fernando El Católico, 1992), 183-194; Morales Ruiz, El discurso antimasónico, 357-359; y Morales Ruiz, Palabras asesinas, $472-475$.
} 
Esta Ley desarrolla una serie de medidas coercitivas del máximo rigor sin ninguna garantía para el encausado. Las penas iban desde la incautación de bienes hasta la reclusión mayor. Los masones, aparte de las sanciones económicas, quedaban automáticamente separados de cualquier empleo o cargo de carácter público.

Se establecieron penas de veinte a treinta años de prisión para los grados superiores, y de doce a veinte para los cooperadores. Además, todos los encausados deberán realizar una "retractación", y en caso de negarse se agravarán las penas. ${ }^{36}$ Veamos el texto literal de la Ley:

Acaso ningún factor, entre los muchos que han contribuido a la decadencia de España, influyó tan perniciosamente en la misma y frustró con tanta frecuencia las saludables reacciones populares y el heroísmo de nuestras Armas, como las sociedades secretas de todo orden y las fuerzas internacionales de índole clandestina.

Entre las primeras, ocupa el puesto más principal la masonería, y entre las que, sin constituir una sociedad secreta propiamente, se relacionan con la masonería y adoptan sus métodos al margen de la vida social, figuran las múltiples organizaciones subversivas en su mayor parte asimiladas y unificadas por el comunismo.

En la pérdida del imperio colonial español, en la cruenta guerra de la Independencia, en las guerras civiles que asolaron a España durante el pasado siglo, y en las perturbaciones que aceleraron la caída de la Monarquía constitucional y minaron la etapa de la Dictadura, así como en los numerosos crímenes de Estado, se descubre siempre la acción conjunta de la masonería y de las fuerzas anarquizantes movidas a su vez por ocultos resortes internacionales.

Estos graves daños inferidos a la grandeza y bienestar de la Patria se agudizan durante el postrer decenio y culminan en la terrible campaña atea, materialista, antimilitarista y antiespañola que se propuso hacer de nuestra España satélite y esclava de la criminal tiranía soviética.

Al levantarse en armas el pueblo español contra aquella tiranía, no cejan la masonería y el comunismo en su esfuerzo. Proporcionan armas, simpatías y medios económicos a los opresores de la Patria, difunden, so capa de falso humanitarismo, las más atroces calumnias contra la verdadera España callan y escuchan los crímenes perpetrados por los rojos, cuando no son cómplices en su ejecución y, valiéndose de toda suerte de ardides y propagandas, demoraron nuestra victoria final y prolongaron el cautiverio de nuestros compatriotas.

Son muy escasas y de reducido alcance las Órdenes y disposiciones legales adecuadas para castigar y vencer estas maquinaciones. El Decreto de 19 de Julio de 1934, resultó

\footnotetext{
${ }^{36}$ Por las características de esta Ley creo que se puede englobar en el llamado "derecho penal del enemigo". Esta figura jurídica fue acuñada por el jurista alemán Günther Jakobs en 1985. La usó para referirse a los momentos en los que un Estado utiliza su derecho penal como herramienta para luchar contra un enemigo en lugar de usarlo para juzgar a uno de sus ciudadanos. Se caracteriza por una pérdida de la proporcionalidad en las penas, la reducción de los derechos fundamentales y garantías del procesado, así como la criminalización de conductas que realmente no suponen ningún peligro.
} 
ineficaz por su vaguedad al enunciar el delito o por circunscribirse a un determinado sector.

Sin que, por ahora, se pretenda establecer la normativa definitiva y total sobre esta materia, se hace ya indispensable determinar la calificación jurídica y sanciones que merecen los que todavía secundan la masonería o el comunismo y demás sociedades secretas y organizaciones contrarias al orden social.

Con ello se pone un valladar más firme a los últimos estertores de las fuerzas secretas extranjeras en nuestra Patria y se inicia la condenación social de las organizaciones más perniciosas para la unidad, grandeza y libertad de España.

Más en estas disposiciones no se debe olvidar la conducta de los que, habiendo pertenecido ocasionalmente a dichas entidades, reaccionaron a tiempo y rompieron con ellas para entregarse denodadamente al servicio de la Patria, lavando a veces con sangre heroica los yerros cometidos. "Acogiendo tales postulados, no hacemos sino mantenernos fieles a los principios cristianos y a la generosidad del Movimiento Nacional.

En su consecuencia DISPONGO:

Artículo $1^{\circ}$.-

Constituye figura de delito, castigado conforme a las disposiciones de la presente Ley, el pertenecer a la masonería, al comunismo y demás sociedades clandestinas a que se refieren los artículos siguientes. El Gobierno podrá añadir a dichas organizaciones las ramas o núcleos auxiliares que juzgue necesario y aplicarles entonces las mismas disposiciones de esta Ley debidamente adaptadas.

Artículo $2^{\circ}$.-

Disueltas las indicadas organizaciones, que quedan prohibidas y fuera de la Ley, sus bienes se declaran confiscados y se entienden puestos a disposición de la jurisdicción de responsabilidades políticas.

Artículo $3^{\circ}$.-

Toda propaganda que exalte los principios o los pretendidos beneficios de la masonería o del comunismo o siembre ideas disolventes contra la Religión, la Patria y sus instituciones fundamentales y contra la armonía social, será castigada con la supresión de los periódicos o entidades que la patrocinasen e incautación de sus bienes, y con pena de reclusión mayor para el principal o principales culpables, y de reclusión menor para los cooperadores.

Artículo $4^{\circ}$.-

Son masones todos los que han ingresado en la masonería y no han sido expulsados o no se han dado de baja de la misma o no han roto explícitamente toda relación con ella, y no dejan de serlo aquéllos a quienes la secta ha concedido autorización, anuencia o conformidad, bajo cualquier forma o expediente, para aparentar alejamiento de la misma. A los efectos de esta Ley se consideran comunistas los inductores, dirigentes y activos colaboradores de la tarea o propaganda soviética, trotskistas o similares. 
Artículo $5^{\circ}$.-

A partir de la publicación de esta Ley, los delitos de masonería y comunismo definidos en el artículo cuarto serán castigados con la pena de reclusión menor. Si concurriera alguna de las circunstancias agravantes expresadas en el artículo sexto, la pena será de reclusión mayor.

Artículo $6^{\circ}$.-

Son circunstancias agravantes dentro de la calificación masónica, el haber obtenido alguno de los grados del 18 al 33, ambos inclusive, o el haber tomado parte en las asambleas de la asociación masónica internacional y similares o en las asambleas nacionales del Grande Oriente Español, de la gran logia española o de otras cualesquiera organizaciones masónicas residentes en España, o el haber desempeñado otro cargo o comisión que acredite una especial confianza de la secta hacia la persona que la recibió. Son circunstancias agravantes, dentro del comunismo, el figurar en los cuadros de agitación, en las jefaturas y en los núcleos de enlace con las organizaciones extranjeras y el haber participado activamente en los congresos comunistas nacionales o extranjeros.

Artículo $7^{\circ}$.-

Quienes en tiempo anterior a la publicación de esta Ley hayan pertenecido a la masonería o al comunismo, en los términos definidos por el artículo cuarto, vienen obligados a formular ante el Gobierno una declaración-retractación en el plazo de dos meses y conforme al modelo que las disposiciones reglamentarias establezcan, en la cual se haga constar aquel hecho así como las circunstancias que estimen pertinentes $\mathrm{y}$, señaladamente, si concurriese alguna de ellas, las determinadas en los artículos sexto y décimo.

Artículo $8^{\circ}$.-

Sin perjuicio de la persecución de otros delitos que hubieran cometido las personas comprendidas en el artículo anterior, aquéllas en que no se reconozca alguna excusa absolutoria, quedarán separadas definitivamente de cualquier cargo del Estado, Corporaciones públicas $\mathrm{u}$ oficiales, entidades subvencionadas $\mathrm{y}$ empresas concesionarias, gerencias y consejos de administración de empresas privadas, así como cargos de confianza, mando o dirección en las mismas, decretándose, además, su inhabilitación perpetua para los referidos empleos y su confinamiento o expulsión. Asimismo, serán sometidos a procedimiento para imposición de sanción económica, conforme a la Ley de 9 de febrero de 1939. Se considerará circunstancia atenuante el suministrar información o datos interesantes sobre actividades de la secta, sobre los que iniciaron o fueron jefes o compañeros en ella del declarante y, en general, sobre otros extremos que puedan servir con eficacia al propósito de la presente Ley.

Artículo $9^{\circ}$.-

Si no presentasen declaración retractación a que se refiere el artículo séptimo, dentro del plazo indicado, o facilitasen datos falsos u ocultasen aquellos otros que, conocidos por el interesado, tuviese éste obligación de declarar, quedarán sujetos a las sanciones 
previstas en el artículo quinto, sin que puedan beneficiarse de las excusas absolutorias a que se refiere el artículo siguiente.

Artículo $10^{\circ}$.-

Sin perjuicio de la obligación de presentar la declaración retractaria prevenida en el artículo séptimo, podrán considerarse excusas absolutorias que eximan de las medidas y sanciones del artículo octavo, las siguientes: a) Haber servido como voluntario desde los primeros momentos en que hubiera sido posible en los frentes de guerra, durante más de un año, ya en los Ejércitos nacionales, ya en las Milicias, y con cualquier grado, observando, además conducta ejemplar en todos los órdenes, a juicio de sus jefes, y, en su caso, de sus compañeros de armas. En el caso de que se trate de personal en quien haya concurrido esta circunstancia, con carácter distinto del voluntario, como profesionales o movilizados, se podrá apreciar la excusa absolutoria si, además, se hubieran distinguido especialmente en el frente a juicio también, de los jefes y de los compañeros de armas, en su caso. b) Haberse sumado a la preparación o realización del Movimiento Nacional con riesgo grave y perfectamente comprobado. c) Haber prestado servicios a la Patria que, por salirse de lo normal, merezcan dicho título de excusa.

Artículo $11^{\circ}$.-

Para decretar las medidas a que se refiere el artículo octavo, así como para apreciar la concurrencia de excusas absolutorias del décimo, cuando se trate de militares profesionales de categoría igual o superior al de oficial de los Ejércitos de Tierra, Mar, o Aire, serán competentes los Tribunales de Honor, constituidos y funcionando conforme a las normas de sus respectivos Institutos. Las actas de dichos Tribunales serán elevadas al Consejo Superior del Ejército para su aprobación a los efectos, no sólo de mantener la pureza del procedimiento, sino también la necesaria unidad de criterio en cuanto al fondo, pudiendo por este motivo someter los fallos a revisión de un Tribunal mixto compuesto por representaciones de los Ejércitos de Tierra, Mar y Aire. A los fines de este artículo el Consejo Superior del Ejército funcionará ampliado con un representante del de Mar y otro del Aire.

Artículo 12.-

Cuando se trate de otras personas no comprendidas en el artículo anterior, el decretar las medidas indicadas y apreciar la concurrencia de excusas absolutorias corresponderá a un Tribunal especial presidido por quien libremente designe el Jefe del Estado y constituido, además, por un General del Ejército, un jerarca de Falange Española Tradicionalista y de las JONS y dos letrados, nombrados todos del mismo modo. No obstante, la apreciación de la concurrencia de las circunstancias prevenidas en los apartados b) y c) del artículo décimo, corresponderá al Consejo de Ministros, a propuesta del Tribunal. El Tribunal podrá comisionar la instrucción de expedientes y sumarios a los jueces de la jurisdicción ordinaria y a los de Ejército, Marina y Aire que se le adscriban a dicho efecto. Y previa celebración de juicio, con audiencia de un fiscal y del interesado, dictará sentencia. Contra ella podrá interponerse recurso en 
término de diez días, ante el Consejo de Ministros, por quebrantamiento de forma, error de hecho o injusticia notoria.

Artículo $13^{\circ}$.-

La persecución de los delitos comprendidos en los artículos tercero, cuarto y noveno de la presente Ley se atemperará en todo caso a las normas de competencia y procedimiento señaladas en el artículo 12.

Artículo $14^{\circ}$.-

Quedan derogadas cuantas disposiciones se opongan a los artículos que anteceden.

\section{Sobre la promulgación de la Ley y la creación del TERMC}

La Ley de Represión de la Masonería y el Comunismo fue saludada con entusiasmo por los periódicos de la España de Franco. Vamos a recordar algunos ejemplos.

En el periódico Madrid se publica un editorial de un marcado carácter antisemita:

La masonería es un instrumento con el que una raza perfectamente definida, actualmente aliada a un poderoso Imperio, procura dominar por dentro a todos los demás países, constituyéndose en ellos cuadros de mando para todas las actividades de la vida social -incluso de la castrense - obedientes y sumisos a sus órdenes.

Lo que hace intolerable para toda la nación soberana que no sea la directamente favorecida por esa institución, la existencia de la masonería es el hecho de que sus afiliados juren y presten obediencia a un jefe misterioso, anónimo y extranjero, que por ello puede obligarles, y a menudo les obliga, a proceder contra los intereses de su propia Patria. Ser masón es aceptar la eventualidad de traicionar a su propio país, si así conviene al jefe o al grupo de jefes desconocidos que están en la cúspide de esa organización secreta. [...]

Casi todos los personajes de la ignominiosa y extinguida República española eran masones. La resistencia que han opuesto y los estragos que han causado en el país en servicio directo de la raza y el Imperio que a través de los siglos se interesan en mantenernos disminuidos - son prueba de que la masonería, desde su punto de vista, los había elegido bien.

Es por medio de la masonería como se instituye la tutela sobre las clases medias de una nación, sobre el profesorado, sobre la oficialidad del Ejército; como por medio del marxismo esa raza impone su dominio sobre las clases populares. Así se cierra el ciclo completo de armas subterráneas con que se mantiene sujeta a una nación aparentemente soberana. Por eso la primera labor, la más urgente, cuando se recobra la independencia, es destruir hasta su raíz los gérmenes de ambas organizaciones ${ }^{37}$.

En el periódico católico $Y a$ se habla del “deber” de combatir la masonería:

\footnotetext{
${ }^{37}$ Editorial publicado en el periódico Madrid el 24 de febrero de 1940.
} 
Una ley contra la Masonería puede llamarse también una ley de defensa de España, pues, aunque la Masonería ha actuado con intensidad dondequiera que le resultaba factible oponerse a la civilización cristiana y facilitar la disolución social, ha dedicado a España una enemistad más honda.

El hecho es sumamente honroso para nuestro país, pero dado que es un hecho indiscutible, no cabe la menor duda sobre el deber de un Gobierno de oponerse a los manejos del solapado enemigo. Nos sentimos muy honrados, pero... muy dispuestos a vigilar. La reseña histórica de los daños que a nuestra Patria ha inferido la Masonería es demasiado larga y demasiado fácil.

La Masonería dejó sentir sus efectos entre nosotros en el siglo XVIII, nos llevó a la plena descomposición del tercer cuarto del siglo XIX y lo que, hoy por hoy, tiene mayor interés, se hallaba apoderada de todos los resortes de la Autoridad y encaramada en las alturas del Poder al llegar el momento del glorioso 18 de julio de $1936^{38}$.

En el periódico falangista "Arriba" se saluda la creación del Tribunal de Represión de la Masonería, en clave internacional:

Las victorias del Eje - que son las de la nueva europeidad - penetran a fondo en los pueblos y en las conciencias, tornan la geografía política a sus normales confines y coadyuvan a que las multitudes adopten el nuevo modo de ser, encarecido por nuestro José Antonio. Con todo, la ruina de los sistemas y de los procedimientos plutodemocráticos tiene que adquirir su mayor eficacia, por la inutilización de los hombres que los han encarnado. [...]

Los enemigos de España están en el trance de comprender que la ruina de los sistemas $\mathrm{y}$ de los procedimientos engendra en los pueblos la reacción violenta contra los tiranos de la gran industria internacional, de las finanzas, de los parlamentos y de la masonería. Las multitudes se alzan contra ellos. Si en Francia permanecen -de grado o por fuerza mayor - gentes que colaboraron a la debacle, hay también, a la hora presente, numerosos emigrados que esperan el momento de saltar sobre el Atlántico a bordo de los aviones "Clippers".

En Lisboa una fauna internacional, de raza europea y hebraica - la misma que postuló una conspiración abierta y resuelta contra Franco y las armas de España - aguarda el instante de trasladarse a una América, en cuyo porvenir se insinúan trances cruciales. Europa se siente aliviada de esa carga, de ese lastre acumulado por veinte años de política y economía despóticas.

Esperan hasta diciembre el pasaje de los "Clippers", los ginebrinos, los masones, los judíos, los plutócratas internacionalistas, los magnates que sostenían a las Internacionales marxistas, los inspiradores de la balcanización europea, los sugeridores de secesionismos...

\footnotetext{
${ }^{38}$ Editorial publicado en el periódico católico Ya de Madrid, el 25 de febrero de 1940.
} 
Europa ya no tiene ningún vínculo con esas gentes. Nosotros las vencimos en los campos de batalla, y el Eje ha proseguido gloriosamente la ofensiva de Franco contra todas las fuerzas y castas que traicionaron y envilecieron el genio del Continente. [...] No. Es imposible que ante el espectáculo de la definitiva derrota de los enemigos de España y de la auténtica unidad europea, podamos tener un gesto de conmiseración, de olvido, o siquiera de desprecio.

Se trata de nuestros enemigos seculares, de los que interpretaron y estimularon odios y divergencias de tipo religioso, económico, político y geográfico. Los pasajeros del "Clipper" son nuestros constantes enemigos. Y es natural que les deseemos el paradero que merecen los que pretendieron arrebatarnos la razón y el modo de ser españoles ${ }^{39}$.

Y finalmente en la revista "Fotos", de clara influencia nazi, se alerta contra el peligro de los "falsos conversos":

El reciente nombramiento de un Tribunal especial para reprimir y extirpar del suelo patrio la cizaña masónica, pone otra vez en primer plano un tema de perenne trascendencia política. La masonería es el enemigo natural de la revolución española. Tanto que, sin su funesto influjo en la política y en la economía nacionales, estaríamos ya, a estas alturas de la postguerra interior, en vías de entera recuperación. Pero ahí está, visible en sus efectos - el estraperlo, el retraimiento del capital, la insidia contra los mandos, el chiste derrotista, el secreto anhelo contrarrevolucionario - la obra de la masonería. Fuerza de indudable terquedad en el empeño, utiliza todos los medios, aun los más santos, para el logro de su propósito subversivo.

Hasta la piedad y misericordia cristianas se disfrazan para atacar solapadamente la autoridad severa del Estado. En todas las instituciones y clases sociales ha imbuido máximas y deslizado raíces. ¿No vemos, efectivamente, coaligados contra la justiciera intención de la Falange al católico y al izquierdista de toda la vida?

Amigados andan, por esas tertulias de murmuradores y agiotistas del chisme, gentes que jamás podrán casar en matrimonio fecundo ni sus ideas ni sus intereses.

Un propósito negativo las une: su antifalangismo. Y lo peor no está en su nefanda juntaza, sino en el desconcierto que, con cuentos y corrosivas críticas, siembran entre los que debiera ser irrompible camaradería de la Falange. A fuer de sinceros, hemos de confesar que las fuerzas secretas de la anti-España han logrado, en algunos casos de desgracia, ofuscar las mentes, agriar los corazones y escindir la unidad, que es el modo de ser de nuestra Falange.

La masonería, que, en el duro campo de la lucha armada, perdió, una por una, todas las batallas, ha visto, en los primeros difíciles pasos hacia la paz total, compensados algunos de sus desastres con éxitos conseguidos; más que por su coraje - del que carece - por la obcecación e ingenuidad de nuestros camaradas.

\footnotetext{
${ }^{39}$ Editorial publicado en el periódico falangista madrileño Arriba el 12 de septiembre de 1940, con ocasión de
} la creación del Tribunal Especial de Represión de la Masonería. 
Y es hora ya de que aprenda la Falange a obrar con astucia para descubrir -cosa nada fácil - las madrigueras desde las cuales acecha la Internacional masónica, a sueldo de las grandes democracias y orientada por la brújula del Talmud hebraico.

Hemos de reconocer - porque, aunque dolorosa, es la verdad - que el virus masónico ha penetrado incluso en nuestras filas y corrompidos miembros de sana y auténtica prosapia falangista. El mal no está precisamente en el suceso de tal desgracia - que corruptible es la naturaleza del hombre - sino en la complicidad o cobardía del consentimiento. [...]

La masonería es morbo que no se cura con antídotos sino sajando y amputando con cirugía de hierro. Al masón de hecho no le podemos dar tregua ni armisticio ni paz: lucha a muerte es lo que únicamente cabe. Pero tampoco se ha de ablandar nuestro ánimo con el masón "convertido" o simplemente "retractado".

Aparte de que el arrepentimiento puede ser ficticio, hemos de pensar que la masonería es un "modo de ser" de tal naturaleza que, aun suponiendo sincera la conversión, perduran en el "converso" la tendencia, la configuración mental, el clima ético.

Y, sobre todo, quedan en el "converso" relaciones de amistad que influirán en su querer, en su juicio y hasta en su acción. De ningún modo debería admitirse a cargos y tareas de responsabilidad política al que alguna vez confraternizó con los "Hijos de la viuda". Siempre actuará en forma sinuosa, escéptica, insincera. El "hábito" no se pierde sino con largo ejercicio en contra ${ }^{40}$.

\section{Regulación de la declaración-retractación}

En el artículo 7 de la ley de Represión de la masonería se obligaba a los masones a realizar una retractación. En el mes de abril de 1940 se publicó un decreto regulando estas retractaciones, en las que lo fundamental, junto la propia retractación, será la obligación de facilitar información que pueda servir para combatir a la masonería. Mejor que ningún comentario es la publicación del articulado de este decreto.

Art. 1.- Todo español o extranjero residente en España que antes del día 2 de marzo de 1940 haya ingresado en la Masonería está obligado a formular ante el Gobierno una declaración-retractación comprensivas de los siguientes extremos:

1. Nombre, apellidos, estado civil, vecindad, domicilio y profesión del interesado, con expresión de la categoría, clase y empleo si se trata de militar o funcionario.

2. Cargos o destinos que desempeña en la actualidad en el Estado, corporaciones públicas u oficiales, entidades subvencionadas y empresas concesionarias, incluso en Consejos de Administración.

3. Declaración del lugar y la fecha en que ingresó en la Masonería y de la persona por quien fue iniciado.

4. Nombre simbólico que tuvo y grado que alcanzó.

5. Jefes o Grados superiores a los que está subordinado.

6. Talleres, logias o grupos a los que ha pertenecido.

\footnotetext{
${ }^{40}$ Editorial publicado en la revista Fotos el 14 de septiembre de 1940.
} 
7. Sesiones o reuniones a que ha asistido con expresión especial de las asambleas ordinarias o extraordinarias, nacionales o internacionales.

8. Cargos o comisiones que ha desempeñado en la secta.

9. Razones que tuvo para ingresar.

10. Información o datos interesantes sobre actividades de la secta, sobre jefes o compañeros en ella del declarante y sobre extremos que puedan servir con eficacia a la represión de la Masonería.

11. Si el declarante ha dejado de pertenecer a la secta; desde que fecha, en virtud de acto, por resolución, porque motivo, forma que revistió y cuantas circunstancias crea pertinentes en relación con la baja, separación o apartamiento.

12. Si concurre en el interesado alguna de las circunstancias de artículo 10 de la Ley (haber servido como voluntario de los frentes de guerra defendiendo la Causa Nacional, la conducta ejemplar en todos los momentos etc.).

13. Declaración de si por cualquier jurisdicción ha sido objeto de sanción y de que clase y cuantía por su condición de masón.

14. Retractación explicita del declarante por la que manifiesta que tiene rotos o rompe todos sus compromisos con la secta, abjurando de sus errores o ratificación, abjuración anterior.

15. Cuantas manifestaciones crea convenientes en relación con los extremos precedentes.

16. Juramento de que cuanto se contiene en la declaración-retratación es verdad y de que en ella no se ha omitido nada de lo que en la Ley de 1 de marzo de 1940 se dispone.

Art. 2.- La obligación de presentar la declaración-retratación se extiende incluso a los que con anterioridad al 18 de julio de 1936 hubiesen sido expulsados de la Masonería, dados de baja o hubiesen roto explícitamente con ella.

Art. 3.- El plazo de 2 meses para la prestación de la declaración-retractación comenzará a contarse a partir del día siguiente a la publicación de esta Orden en el Boletín Oficial del estado.

Art.4.- La declaración-retratación habrá de presentarse: Por los militares profesionales en activo, reserva o cualquiera que sea su situación, ante el General Jefe de la Región Militar, Comandancia General o Jefe Superior de las Fuerzas Militares en Marruecos en su caso, si se trata de Ejército de Tierra; ante el Comandante General del Departamento Marítimo y Almirante de la Escuadra si se trata del Ejercito de Mar; ante el correspondiente Jefe de la Región o Zona Aérea si se trata del Ejército del Aire; y ante el Director General si se trata de la Guardia Civil o Carabineros. En caso de tratarse de personal con destino en la Administración Central se hará ante las Secretarias Generales de los distintos departamentos ${ }^{41}$.

${ }^{41}$ Decreto 2, del 30 de marzo de 1940, Presidencia, BOE 12, no. 688, 3 de abril que desarrolla la aplicación de la Ley del 1 de marzo de 1940. 


\section{Declaración-retractación}

Los masones debían presentar obligatoriamente dos meses después de la publicación de la Ley de Represión de la Masonería un documento de retractación al que debían añadir la siguiente declaración firmada:

La Santa Madre Iglesia Católica, Apostólica, Romana, es la única y verdadera Iglesia fundada por Jesucristo en la Tierra, a la cual de todo corazón me someto.

Creo en todos los Artículos que me propone creer; repruebo y condeno cuanto Ella reprueba y condena y esto pronto a observar cuanto me manda, y especialmente prometo creer en:

La doctrina católica sobre la Encarnación, Pasión, Muerte y Resurrección de Nuestro Señor Jesucristo y la unión hipostática de las dos naturalezas, divina y humana;

La divina maternidad de María Santísima, así como su integérrima virginidad e Inmaculada Concepción;

La presencia verdadera, real y sustancial del Cuerpo, juntamente con la Sangre, Alma y Divinidad de Nuestro Señor Jesucristo en el Santísimo Sacramento de la Eucaristía; Los siete sacramentos instituidos por Jesucristo para salvación del género humano, a saber: bautismo; confirmación; eucaristía; penitencia; extremaunción; orden sacerdotal; y matrimonio;

El purgatorio, la resurrección de los muertos, la vida eterna;

El Primado de Pedro, no tan solo de honor, sino también de jurisdicción, del Romano Pontífice, sucesor de San Pedro, Príncipe de loa Apóstoles y Vicario infalible de Cristo;

El culto de los Santos y de sus imágenes;

La autoridad de las apostólicas y eclesiásticas tradiciones y de las Sagradas Escrituras, que no deben interpretarse y entenderse sino en el sentido que ha tenido y tiene la Santa Madre Iglesia Católica;

Y todo lo demás que por los Sagrados Cánones y por los Concilios Ecuménicos, especialmente por el Sagrado Concilio Tridentino y por el del Vaticano ha sido definido y declarado.

\section{Sobre el Tribunal Especial para la Represión de la Masonería}

En el artículo 12 de la Ley de Represión de la Masonería se establece la creación y composición del Tribunal Especial para la Represión de la Masonería: un presidente, un general del Ejército, un jefe de Falange y dos letrados, todos ellos nombrados por el jefe del Estado.

Su primer presidente fue Marcelino de Ulibarri (Decreto de 4 de junio de 1940), poniendo en íntima conexión el tribunal con el organismo que iba a facilitarle la información para juzgar a las personas: la Delegación del Estado para la Recuperación de Documentos, que dirigía el propio Ulibarri. Disponía de un archivo de expedientes personales, que posteriormente pasó a depender del responsable de la Delegación Nacional de Servicios 
Documentales, quien tenía como misión el envío de informes para abrir los expedientes

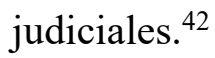

Se trataba de una jurisdicción especial, bajo la dependencia de la Presidencia del Gobierno, que juzgaba los delitos tipificados por la ley de represión de la masonería. El 31 de marzo de 1941 fue cesado como presidente Marcelino de Ulibarri, pasando a desempeñar el puesto de vocal-ponente, y es sustituido por don Andrés Saliquet Zumeta. Fue en ese año, cuando comenzó el funcionamiento efectivo del tribunal centrándose sus dos juzgados en atender al delito de masonería.

En 1942 se constituye un tercer juzgado que inicia los procesos por el delito de comunismo. La ley estuvo vigente hasta el 2 de diciembre de 1963, en que se suprimió el tribunal especial y se formó una comisión liquidadora que llegó a funcionar hasta 1971.

El Tribunal Especial funcionó, en la mayoría de los casos sin las más mínimas garantías jurídicas, si nos atenemos a las indicaciones que realizó por escrito, Marcelino Ulibarri y Eguilaz, su primer presidente, con objeto de orientar las actuaciones del Tribunal que iba a juzgar a los masones españoles:

El procedimiento ha de ser especial, como especial es la Ley y especialísimo el enemigo contra el cual esta se dirige y con el que habrá que luchar certeramente para que ella se cumpla. Porque no debe olvidarse que se trata de sancionar a personas adiestradas muchas de ellas en la más fina y astuta habilidad para conseguir sus fines. $\mathrm{Y}$ todas hermanadas entre si sólidamente con compromisos de mutua ayuda que producirá cuando menos asesoramientos y consejos recíprocos sobre el modo de defenderse de la Ley, comunicándose entre sí todas las vicisitudes y circunstancias del proceso de cada uno cuyo conocimiento pueda servir a los demás.

Ya que contra la Masonería no se haya optado por emplear ahora gubernativamente un procedimiento directo, eficaz y general del tipo de los que en siglos gloriosos del Imperio aplicaron los Reyes Católicos para librar a España de Judíos o Felipe III cuando alejó del porvenir de la Patria el peligro que para ella entrañaban los moriscos, adóptese un procedimiento judicial si se quiere, pero adecuado por su simplificación y eficiencia para el caso.

Habrá que huir de la excesiva preocupación legalista que llenará el procedimiento de requisitos formales, plazos, trámites, escritos, vistas y recursos.

Óigase a los enjuiciados en la forma estricta (sic) suficiente para llenar la exigencia natural de no condenar a nadie sin ser oído y a fin de poder utilizar las manifestaciones de los interesados como elementos de juicio; admítaseles prueba documental en tanto en cuanto no pueda esgrimirse su propuesta como medio de entorpecer la marcha del

\footnotetext{
${ }^{42}$ Hay una Circular para cumplimentar la ejecución de Ley de Represión de la Masonería, emanada desde el Ministerio de la Presidencia, y que lleva el n $^{\mathrm{o}}$ de orden 12.674, emitida el 28 de abril de 1941 (BOE de 29 de abril de 1941). En ella "se dispone que todos los documentos y ficheros de carácter masónico que obren en poder de organismo oficiales y de personas particulares sean remitidos al Archivo de dicho Tribunal (-Tribunal de Represión del Comunismo y la Masonería-) que se encuentra instalado en Salamanca donde quedaran depositados."
} 
proceso, pero regúlese este en todo con la natural suspicacia de que los enjuiciados tratarán de prevalerse hábilmente de las mismas disposiciones legales para poder dilatar cuanto puedan toda resolución del Tribunal contra ellos.

No vaya a incurrirse en el pueril error de trasladar al procedimiento que para esa Ley se establezca, los preceptos legales de nuestra Ley de Enjuiciamiento criminal, ni aun siquiera los principios que la inspiran, tan distintos de los que exige la represión contra la Masonería.

Porque ha de tenerse en cuenta que no se trata de averiguar si se cometió o no un cierto hecho objeto de denuncia cuya comprobación sea necesaria. Se parte de la base de existir prueba documental inequívoca que acredita la condición de masón en el residenciado y a veces las actividades y vicisitudes que en la Secta tuviera.

El inmenso archivo Especial pacientemente formado, que debe quedar afecto al mismo Tribunal como base esencial indispensable para actuar este, contiene los cargos concretos que desde luego contra cada individuo se formulan.

El objeto de ulteriores investigaciones queda reducido a analizar la retractación si la hubo, y las pruebas primordialmente documentales que puedan aducirse por los interesados para demostración de las excusas absolutorias que aleguen. (...)

Y nada de exigir la intervención de Letrado, ni de consentir debates orales, ni de vistas públicas. Los propios masones dan la pauta de cómo se les debe juzgar.

Las medidas que ellos adoptaban para perseguir y combatir a los profanos (...) eran acuerdos tomados con la mayor clandestinidad y disimulo sin que los propios perseguidos pudieran enterarse siquiera de que procedía su persecución de la Masonería, introducida en todas partes y sin apariencia externa, como los gases.

\section{Dos ejemplos de la retórica represiva antimasónica de Franco}

Finalizaremos con dos ejemplos de la retórica represiva de Franco en clave antimasónica. El primero es un artículo titulado "La masonería actual", publicado en el periódico Arriba, con el pseudónimo de Jakin Boor, el 3 de mayo de 1951.

El segundo es el último discurso pronunciado el 1 de octubre de 1975, desde el balcón del Palacio Real, ante una multitud que le vitoreaba en la Plaza de Oriente. Fue publicado por todos los periódicos españoles el 2 de octubre de 1975. Varias semanas después fallecía el 20 de noviembre de 1975. Los dos reflejan su obsesión antimasónica que llegó hasta el delirio.

\section{La masonería actual}

Se vive en nuestros días tan de prisa, cuando no tan frívola y superficialmente, que pocos son los que se toman la molestia de detenerse a analizar el porqué de los hechos, y hasta lo que nos sorprende, afecta e impresiona es rápidamente olvidado, como si el alejamiento de los hechos pudiera hacer desaparecer las causas perennes que les dieron vida.

Esto ocurre con la masonería. Gravísimos son los daños que a nuestra sociedad han venido infiriendo sus conspiraciones; gravísimas las pruebas contundentes e incontrovertibles que hemos venido acumulando en nuestros trabajos anteriores, que 
demuestran de manera fehaciente que la masonería no descansa; que desde que nació siguen siendo sus blancos la Iglesia Católica y el resurgimiento de España.

Que existe un Comité supremo en Europa, titulado Asociación Masónica Internacional, a través del cual se conspira en forma ininterrumpida, y un día tras otro, contra cuanto España representa, a la vez que se utiliza como instrumento de la acción política de algunas naciones europeas contra Norteamérica, cuya masonería, aunque apartada de la Asociación, no es impermeable a la influencia que este instrumento secreto de poder desarrolla sobre las logias hispanoamericanas para servir a los designios secretos de sus señores.

Muchas veces hemos repetido, saliendo al paso de las quejas que las masonerías extranjeras, en especial las anglosajonas, suelen exteriorizar contra nuestros documentados trabajos, que forzosamente tiene que ser muy distinto el juicio que de la masonería puedan formar los verdugos y las víctimas: aquellas naciones para las cuales la masonería constituye un órgano eficaz de su acción contra otros pueblos, y los que de éstos vienen sufriendo durante más de un siglo las conspiraciones que la masonería desde el exterior les desata; no pueden pensar lo mismo de ella aquellos cristianos disidentes de la fe católica que la masonería misma, que los católicos que durante siglos vienen sufriendo los ataques y las maquinaciones de sus logias.

En los países en que la masonería es lícita, defiende a la nación y no se encuentra en pugna con el sentir general ni los principios de su fe, la calidad de los que en ella militan forzosamente ha de ser muy distinta que cuando de países católicos se trata y la masonería constituye el instrumento secreto de unos pocos vendidos al servicio del extranjero para la destrucción o anulación de la nación.

En este orden creía haber esclarecido suficientemente desde este diario las características más salientes de la acción masónica sobre España, y cuando me había concedido un descanso en estas tareas tonificadoras de la defensa de nuestra sociedad contra la masonería, nuevas muestras de la actividad masónica vienen reclamando a mi pluma la vuelta a la palestra.

Si la masonería no descansa en sus actividades criminales, forzosamente hemos de ponernos en plan de combatir quienes, por conocerla, nos hemos convertido en fieles guardianes de nuestro solar frente a sus ataques.

No hemos jamás de olvidar que entre las fuerzas derrotadas de la anti-España por el Movimiento Nacional español ocupaban puesto principal las fuerzas masónicas de nuestra Patria, que, aunque reducidísimas en su número, eran, sin embargo, las patrocinadoras de todas las traiciones y las que realmente habían abierto las puertas de la Patria a la invasión comunista y a su enseñoramiento de nuestro solar.

Al hundirse la República, que una minoría exigua de masones había logrado levantar con la estafa del resto de la nación, forzosamente habían de caer aquellos templos masónicos en que, con artificio, malicia y engaño, había venido forjándose la decadencia Española.

En dos grupos dividió a la masonería la guerra: el de los capitostes, que, por haber contraído graves responsabilidades criminales, se exilaron, y aquellos otros que, por no haber tenido una actuación pública y ser en parte desconocidos, se acogieron a la paz y a la generosidad de la nueva España. 
Y mientras los que aquí quedaron parecieron fundirse en la vida ciudadana, disfrutando de la paz y el orden internos de nuestra nación, los otros continuaron fuera de las fronteras la acción criminal antiespañola y fueron los constantes voceros de la BBC británica, de la Radio París y de otras muchas Radios minadas por la masonería o adscritas a su servicio.

Desde entonces, cuantos vientos de fuera nos soplaron han tenido su principal motor en la dispersión de esa criminalidad masónica por las logias del mundo, a las que, después de haber recibido su auxilio, parasitaron con la levadura de su espíritu criminoso.

Los que crean que la masonería se da alguna vez por vencida se equivocan. Hija de la maldad, su espíritu demoníaco sobrevive a la derrota y encarna en nuevos seres y en nuevos territorios. Hemos de desconocernos al sol de la gloria y del resurgimiento si queremos librarnos de la sombra inseparable de las asechanzas masónicas.

Dos razones hay para que la masonería nos ataque: una, la de la independencia española, malquerida no sólo de la masonería propia, sino también de las extrañas, y otra, el resurgimiento del espíritu católico de nuestra nación, que, por católica, apostólica, romana, se convierte en blanco predilecto de la conspiración masónica.

Después de diez años de grandes esfuerzos y fracasos, sentimos hoy de nuevo sobre nuestra Patria la acción disociadora de las logias masónicas. Cuando el horizonte internacional se ofrecía aparentemente más despejado; cuando la vuelta de los embajadores señalaba la derrota de la conspiración masónica, que, jugando "al alimón" con el comunismo, había llevado a cabo la monstruosa conjura de la ONU. En buena hora deshecha por la firmeza del Caudillo y su pueblo, nuevamente aparece en el horizonte la acción conspiradora de la masonería y sus agentes contra la paz y el orden internos de nuestra Patria.

Y mientras las Radios al servicio de Moscú enronquecen en sus propagandas contra la fortaleza del bastión ibérico y los gobernantes masones de las naciones occidentales pretenden subestimar el valor estratégico militar y político de nuestra nación ante las amenazas que el mundo sufre, la acción masónica, que, con habilidad que hemos de reconocerle, maneja los hilos de la intriga, siembra en nuestro solar la disociación y pretende explotar el malestar que la carestía universal y otras circunstancias imperativas proyectan sobre nuestra Patria.

No se trata de nada nuevo, muchos que desde que terminó nuestra contienda la masonería proyecta sobre nuestra nación, y que explotan unos malvados con la inconsciencia colaborante de quienes viven frívola o superficialmente; pero (a los que, sin duda, bastará una voz de alarma para que puedan descubrir en los que tal ambiente forma su nexo, con los masones o sancionados.

¿Que los tiempos no son fáciles? Todos hemos de reconocerlo. ¿Que asistimos a un proceso general de carestía de la vida, que se puede frenar, pero no totalmente dominar? Es evidente.

Que directa o indirectamente estamos todas las naciones pagando la guerra pasada, el plan Marshall y la preparación del arsenal bélico del Occidente, constituye un hecho incontrovertible, ya que todos esos gastos, que importan miles de millones de dólares, a través de los impuestos y de la carestía de los precios, se reparten sobre todas las 
naciones del universo, que, en mayor o menor escala, lo ven repercutir en sus precios interiores.

Quien con autoridad puede decirlo y con clarividencia anunció al mundo males que por torpeza se cosecharon, nos viene previniendo de la importancia de la era social en que vivimos, de la crisis de los viejos sistemas para dar soluciones a los problemas de la hora actual y de la necesidad de abrir cauces a la realización de las aspiraciones latentes en las masas más importantes de la Humanidad, si no queremos caer en el caos materialista y antihumano que el comunismo representa.

En este aspecto político es muy claro el dilema: o nos resignamos a conllevar nuestra escasez en medio de la paz y el orden con vistas a plazo fijo a la mejora ansiada, o caeremos con incomparables mayores estrecheces en el caos y en la anarquía que los masones, consciente o inconscientemente, patrocinan.

Parecería bastar con lo dicho para que la agudeza de los españoles sacase consecuencias de los intentos de agitación que desde la llegada de los embajadores se pretende mover en nuestra Patria; pero no está de más que para los torpes o los maliciosos recordemos su trayectoria y los nexos de la agitación con la secta masónica y las consignas desde fuera; recordaremos a nuestros lectores aquel trabajo, publicado en este mismo diario, en que descubríamos la acción desarrollada en las últimas décadas por la masonería sobre nuestras Universidades.

Aquella Institución Libre de Enseñanza, de nefasta memoria, con la que acaudalados masones torcían el buen natural de nuestros universitarios con becas, bolsas de estudio y un laicismo desaforado; aquella Federación Universitaria de Estudiantes, que si exteriormente asociaba a la casi totalidad de los estudiantes de la nación en una federación escolar universitaria, interiormente estaba manejada y controlada por lo que en el "argot" "masónico titulaban "la FUE interna", constituida por un grupo de estudiantes masones íntimamente ligados con las logias que ocupaban los años 1930 y 1931 los puestos directivos y que, estafando a los otros escolares, vendían su Patria y la Universidad a la traición, y que más tarde, públicamente, bajo la República, se declararon masones y cobraron la cuenta de su traición.

Lo mismo que desde que terminó nuestra Cruzada, a través de catedráticos izquierdistas $\mathrm{y}$ de hijos de masones sancionados o desplazados, ha venido intentándose un día tras otro, y que gracias al patriotismo y buen sentido de una juventud en que la Patria se mira ha podido abortarse.

Los incidentes y algaradas de Barcelona constituyen una muestra de estos torpes empeños, que allí explotan los residuos del viejo separatismo, que las logias francesas amparan y que aún hoy intentan cultivar desde allende el Pirineo.

Otra muestra clarísima de la conexión íntima de masonería y agitación se realza en la explotación que la Prensa masónica del mundo lleva a cabo de sucesos tan triviales y corrientes como las algaradas estudiantiles o los conatos de huelga en tiempos de necesidades y de escasez; cuando en el mundo se desarrollan graves huelgas que paralizan durante muchas semanas la vida de los pueblos, arruinando sus economías y poniendo en peligro la vida entera de la nación, se destaca, multiplica y agranda nuestro más pequeño conflicto laboral, que es muestra precisamente de la tolerancia y de la generosidad de un Régimen que por su fortaleza puede ser generoso. 
En este orden ha quedado bien claro, por la insólita declaración del Comité de Asuntos Exteriores de la Asamblea francesa, compuesto en sus nueve décimas partes de conspicuos masones, la íntima relación de la agitación de la capital catalana y su explotación masónica inmediata.

No trabaja la masonería sólo con fuerzas propias por tratarse de una exigua minoría; su táctica es la de siembra de calumnias, la de dirigir, asociar y agrupar a los descontentos, la acción solapada y traidora, la estafa y explotación de los disgustados. Así, la última consigna que la masonería ha puesto en marcha es la de una supuesta corrupción administrativa, que la malicia humana está siempre dispuesta a acoger, y que, como hemos visto en otras calumniosas campañas desatadas contra la Dictadura y la Monarquía, se demuestra a posteriori haber sido absolutamente falsas.

Nosotros nos creemos llamados a defender el crédito de los pobres y honrados funcionarios españoles, dignos de más respeto y consideración, y cuya moralidad es muy superior a la de la mayoría de los otros pueblos. Si la Administración española no fuese honrada no podría achacársele al Régimen, habíamos de pensar que sus nueve décimas partes y en todos sus escalones superiores más respetables han sido heredados de la Monarquía liberal y de la República y de los tiempos en que la masonería, filtrada en sus filas, compartía las responsabilidades de gobierno.

Es paradójico que la masonería española, que ha recogido en sus filas a los prevaricadores y desfalcadores de todos los Cuerpos del Estado, sea la que intente arrojar el fango sobre la recta Administración española. Y que sea ese mundo democrático de los grandes escándalos de corrupción el que pretenda acoger y divulgar la calumnia que las logias intentan levantarnos.

Precisamente por católico, que sabe que ha de dar cuenta a Dios de sus actos, posee el pueblo español frenos morales desconocidos en otras latitudes en que el materialismo predomina. Si desgraciadamente en todos los países es siempre posible la corruptibilidad humana, Tribunales de Justicia de hombres probos, honrados e independientes están siempre abiertos a la denuncia y a la investigación, como lo pregonan las bajas y sanciones que, en los escalafones, con toda regularidad, se registran.

De todos es conocida la acción que unos grupos incontrolables de masones, sancionados y despechados, realizan cerca de las Embajadas y representaciones diplomáticas extranjeras, a las que se asaetea con cartas simuladas de disgustados, con visitas de elementos indeseables cuya calidad moral queda bien demostrada con esa simple acción de ir a verter en las cancillerías del extranjero los malos humores de su traición. Así se enrarece el ambiente de los diplomáticos extranjeros y se los engaña sobre la calidad moral de nuestro pueblo.

En esta acción de filtración masónica no escapan ni las propias jerarquías eclesiásticas, a las cuales igualmente se pretende influir, como a todos aquellos sectores que cual el Ejército, el Movimiento Nacional o los Sindicatos son considerados por los masones como pilares en que el Régimen se asienta. Alerta, pues, a los masones y los "lowetones" hijos iniciados de aquéllos y a cuantos consciente o inconscientemente se convierten en instrumentos de la anti-España. Que sobre ellos caigan las maldiciones de la Patria. 
El último discurso

Españoles:

Gracias por vuestra adhesión y por la serena y viril manifestación pública que me ofrecéis en desagravio a las agresiones de que han sido objeto varias de nuestras representaciones diplomáticas y establecimientos españoles en Europa, que nos demuestran, una vez más, lo que podemos esperar de determinados países corrompidos, que aclara perfectamente su política constante contra nuestros intereses. No es la más importante, aunque se presenta en su apariencia, el asalto y destrucción de nuestra Embajada en Portugal, realizada en un estado de anarquía y de caos en que se debate la nación hermana, y que nadie más interesado que nosotros en que pueda ser restablecido en ellos el orden y la autoridad.

Todo obedece a una conspiración masónica izquierdista en la clase política en contubernio con la subversión comunista-terrorista en lo social, que, si a nosotros nos honra, a ellos les envilece.

Estas manifestaciones demuestran, por otra parte, que el pueblo español no es un pueblo muerto, al que se le engaña. Está despierto y vela sus razones y confía que la valía de las fuerzas guardadoras del Orden Público, y suprema garantía de la unidad de las Fuerzas de Tierra, Mar y Aire, respaldando la voluntad de la Nación, permiten al pueblo español descansar tranquilo. Evidentemente, el ser español ha vuelto a ser hoy algo en el mundo. ¡Arriba España!

\section{Epílogo}

Escribe Ronald Fraser en el prólogo de su monumental Historia oral de la guerra civil que

volver la espalda al pasado, un pasado tan amargo como éste, siempre es tentador. Pero seguir "olvidando" es olvidar que la España de hoy, a pesar de lo diferente que sea de la de hace sesenta años, ha sido configurada por la Guerra Civil y la dictadura. Para poder llegar a superar verdaderamente este pasado, es necesario comprenderlo y asimilarlo por entero ${ }^{43}$.

En este breve recorrido hemos visto algunos ejemplos documentales del discurso antimasónico durante la guerra y el franquismo. Está lleno de palabras que hacen más daño que las pistolas.

\footnotetext{
${ }^{43}$ Ronald Fraser, Recuérdalo tú y recuérdalo a otros. Historia oral de la guerra civil española (Barcelona: Grijalbo/Mondadori, 1997), vol. I, 1-2.
} 
Son palabras que hieren, son palabras que matan, que hacen un daño inmenso. Palabras asesinas, llenas de odio, llenas de muerte. Ahora que no vienen buenos tiempos para la memoria histórica, debemos de insistir en la necesidad de seguir recordando todavía.

Recordemos la represión de los masones en la España de Franco. Que no se repita nunca más.

\section{Bibliografía}

Álvarez Bolado, Alfonso. Para ganar la guerra, para ganar la paz. Iglesia y guerra civil: 1936-1939. Madrid: Universidad Pontificia de Comillas, 1995.

Baquero, Juan Miguel. El país de la desmemoria. del genocidio franquista al silencio interminable. Barcelona, Roca Editorial, 2019.

Casanova, Julián. La Iglesia de Franco. Barcelona: Crítica, 2005.

Egido León, María de los Ángeles. Los Campos de Concentración Franquistas en el Contexto Europeo. Madrid: Marcial Pons, 2005

Espinosa, Francisco. "Julio de 1936. Golpe militar y plan de exterminio". En Morir, matar, sobrevivir. La violencia en la dictadura de Franco. Coordinado por Julián Casanova. Barcelona: Crítica, 2002.

Ferrer Benimeli, José Antonio. La Masonería en Aragón. Zaragoza: Librería General, 1979.

Ferrer Benimeli, José Antonio. Masonería española contemporánea. Madrid: Siglo XXI de España editores, 1980.

Ferrer Benimeli, José Antonio. La Historia en sus textos. La Masonería española. Madrid: Ediciones Istmo, 1996.

Fraser, Ronald. Recuérdalo tú y recuérdalo a otros. Historia oral de la guerra civil española. Barcelona: Grijalbo/Mondadori, 1997.

García Gual, Carlos. Grecia para todos. Barcelona: Espasa, 2019.

García Serrano, Rafael. La gran esperanza. Nosotros, los falangistas. Barcelona: Planeta, 1983.

González, José Ramón. "Represión, esclavitud y exclusión. un análisis a escala de la violencia franquista”. Entelequia. Revista Interdisciplinar 7 (septiembre 2008): 155.

Hernández de Miguel, Carlos. "Terror en los campos de Franco". El País, 8 de marzo de 2019.

La Cierva, Ricardo de. Historia del franquismo. Barcelona: Planeta, 1976.

Laboa, Juan María. Iglesia e intolerancia: la guerra civil. Madrid: Sociedad de Educación Atenas, 1987.

Morales Ruiz, Juan José. La publicación de la Ley de Represión de la Masonería en la prensa de la España de postguerra (1940) (Zaragoza: Institución Fernando El Católico, 1992 
Morales Ruiz, Juan José. El discurso antimasónico en la guerra civil española (1936-1939). Zaragoza: Departamento de Cultura y Turismo del Gobierno de Aragón, 2001.

Morales Ruiz, Juan José. Palabras Asesinas. El discurso antimasónico en la guerra civil española. Oviedo, Masonica.es, 2017.

Reig Tapia, Alberto. Ideología e Historia: Sobre la represión franquista y la guerra civil. Madrid: Akal, 1986.

Rodrigo, Javier. Cautivos: campos de concentración en la España franquista, 1936-1947. Barcelona: Crítica, 2005.

Vega Sombría, Santiago. De la esperanza a la persecución. La represión franquista en la provincia de Segovia. Barcelona: Crítica, 1985.

Vico, Gil. "Ideología y represión: La Causa General. Evolución histórica de un mecanismo jurídico-político del régimen franquista". Revista de Estudios Políticos (Nueva Época) 101 (julio-septiembre 1998). 